\title{
NetPICOmag: A low-cost networked magnetometer and its applications
}

\author{
I. Schofield ${ }^{1}$, M. Connors ${ }^{1}$, and C. T. Russell ${ }^{2}$ \\ ${ }^{1}$ Centre for Science, Athabasca University, Athabasca, AB, Canada \\ ${ }^{2}$ Institute of Geophysics and Planetary Physics, UCLA, Los Angeles, CA, USA \\ (Received April 1, 2011; Revised September 7, 2011; Accepted October 3, 2011; Online published March 12, 2012)
}

\begin{abstract}
NetPICOmag (NPM) is the culmination of a design effort to build a compact, low-cost, laboratory-grade, networked magnetometer designed for remote autonomous operation, suited for research and education. NPM allows wide placement of magnetometers sensitive enough to detect auroral activity and the daily variation, and is suitable for education projects and a range of geophysical applications. The use of networked microcontrollers and GPS timing is applicable to other small instruments for field or local deployment, and an onboard data logging capability has also been demonstrated. We illustrate the value of the placement of low-cost magnetometers to increase coverage in an area through the study of a Pc 5 pulsation event which took place on September 4, 2010. By combining results with those from auroral zone magnetometers supporting the THEMIS project, we find that the phase velocity of these morning sector pulsations was northward on the ground. The event took place under very quiet solar wind conditions, and credible mapping associates it with the inner magnetosphere. Another aspect beyond increasing areal coverage is increasing density of coverage, which becomes feasible with instruments of very low cost. We examine aspects of the April 5, 2010 space weather event which are possible to deduce from closely spaced magnetometers.
\end{abstract}

Key words: Instrumentation, education, substorm, Pc 5, pulsation.

\section{Introduction}

Modern technology provides unique opportunities for researchers studying the magnetic effects of the aurora and the processes that drive electric currents in the Earth's magnetosphere. Low-cost computers and instrumentation combined with widespread availability of wireless communication in remote regions has made the establishment of networked ground-based magnetometer stations technologically feasible. However, the cost of typical research-grade magnetometers is a significant obstacle to establishing high density, wide coverage magnetic detection networks consisting of many such instruments. We first discuss why such networks are needed.

The history of modern space physics is intimately linked with the ability to accurately measure magnetic fields (Russell, 1995). The diurnal variation, caused mainly by solar heating and easily measured with the instruments discussed below, was discovered through painstaking observation of compass needles by Hiorter in the early 1700s. In 1741, he was the first to make the connection between auroral and magnetic activity, a relation that our equipment would allow students in the auroral zone to see firsthand. As early as the 1830 s, Gauss developed mathematical methods for the separation of internal and external fields, leading to the establishment of magnetic observatories that would allow the study of the fields from both sources.

A major technical step forward was the development of

Copyright (C) The Society of Geomagnetism and Earth, Planetary and Space Sciences (SGEPSS); The Seismological Society of Japan; The Volcanological Society of Japan; The Geodetic Society of Japan; The Japanese Society for Planetary Sciences; TERRAPUB.

doi:10.5047/eps.2011.10.001 the fluxgate magnetometer in 1940 (Vacquier, 1993), which allowed the projection of the magnetic field along its axis to be accurately measured. Fluxgate magnetometers have become the workhorses of geomagnetism, both ground- and space-based. The sensor used in our equipment is commercially available and operates in a manner related to that of fluxgate magnetometers in which a core is driven into saturation.

Magnetic effects due to the daily variation and storms may be observed at any position on Earth, and the causative current systems are large and in general not highly structured as detected from observations at Earth-based locations. By contrast, auroral zone activity can feature structures on very small scales, and the structures which produce perturbations on the ground may be on the scale of auroral arcs. Although there is sometimes an argument made that it is not useful to place magnetometers closer together than the height of the ionosphere, our experience is that spatial scales of the perturbations on the ground can be smaller, notably in the vertical component.

Whether we really need to place magnetometers closer than $100 \mathrm{~km}$ apart is largely a moot point since existing networks have a vastly greater average spacing than this. Many of the fine-scale variations are associated with substorms, which we maintain cannot be adequately characterized from the ground with existing networks. Improving this situation within reasonable budget constraints has been a primary motivating factor in our development of low-cost magnetometers. 


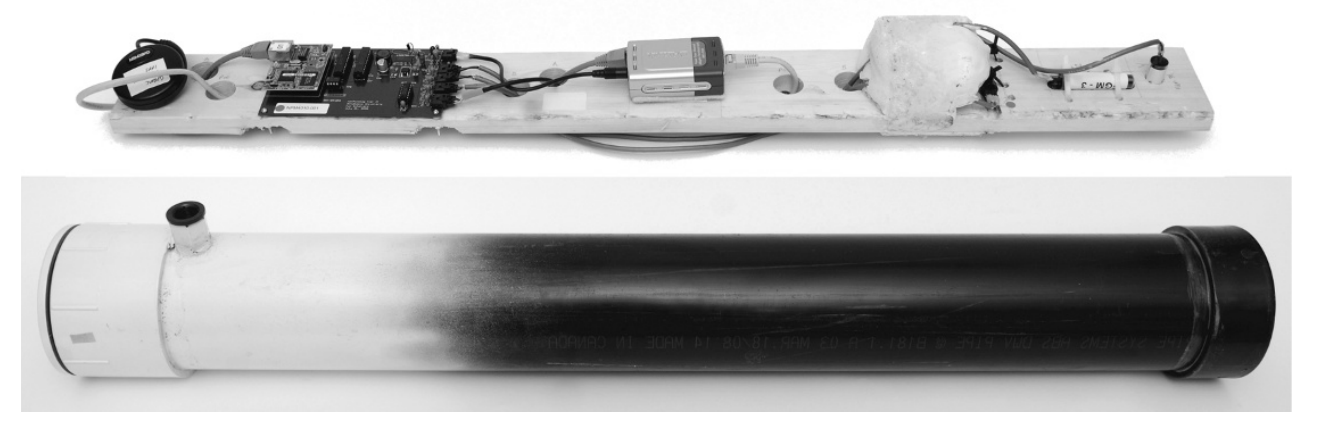

Fig. 1. The NPM internals appearing from left to right, GPS antenna/engine, microcontroller and electronics, Power-over-Ethernet (PoE) terminal unit, polyurethane foam thermal insulation plug, three orthogonally oriented pulse-counting magnetic sensors. The white-colored polyurethane foam plug located between the PoE unit and the magnetic sensors thermally insulates the temperature-sensitive magnetic sensors from heat emanating from the electronics and the upper portion of the enclosure pipe that is exposed above ground. The lower image shows the instrument enclosure, constructed from $100 \mathrm{~mm}$ (4-inch) diameter ABS pipe. A threaded lid on the top of the unit (far left) allows the instrument board to slide out.

\section{Materials and Methods}

Ground based magnetometers are spatially integrating instruments that detect electric currents from sources both nearby and from great distances. A major source of the magnetic fields sensed by these magnetometers, especially in the auroral zones, lies in often narrow currents flowing roughly parallel to lines of constant magnetic latitude. These narrow electrojets are dynamic, changing in time and moving northward and southward as auroral activity develops and evolves. To follow these temporal and spatial developments requires measurements at half the scale imposed by the location of the current (i.e. $100 \mathrm{~km}$ ) so that chains of magnetometers spaced every $50 \mathrm{~km}$ are needed over the latitude band in which the auroral electrojet occurs. This is true not only for quasi-static phenomena but also for traveling waves such as Pc 5 pulsations. Thus the exploration of auroral zone phenomena requires extensive deployment of magnetometers at potentially great cost. Current state-ofthe-art magnetometers can cost many thousands of dollars, limiting the possible density and coverage of ground based magnetometer networks (Bredeson and Connors, 2004) and limiting scientific return. What is needed is a proverbial 500 dollar magnetometer.

This paper discusses the design and results from an ongoing project at Athabasca University whose goal has been to produce a low-cost research-grade magnetometer using digital fluxgate magnetometer technology. NetPICOmag (or NPM) is the latest development in Athabasca University's ongoing low-cost magnetometer project (Connors et $a l ., 2002)$. Such an instrument will permit the development of dense, wide-scale magnetometer observation networks, currently cost-prohibitive with available instrumentation. Increasing the spatial coverage of magnetic sensors across Northern Canada will improve research capabilities and lead to better understanding of the solar-terrestrial processes that produce auroral displays in the ionosphere.

A low-cost magnetometer must possess the following properties in order to be viable. First, it has to yield research-quality magnetic field measurements. This is typically considered to be the ability to detect magnetic perturbations as small as $1 \mathrm{nT}$ sampled once per second $(1 \mathrm{~Hz})$. In comparison, the current model UCLA-built THEMIS Ground Based Observatory (GBO) fluxgate magnetometer can detect perturbations as small as 10 pT (Russell et al., 2008) sampled twice per second $(2 \mathrm{~Hz})$. A low-cost magnetometer must be easy to deploy and involve minimal maintenance. Practically speaking, installation involves burying and aligning the magnetic sensor probe, connecting it to the network, and powering it up. In addition, the unit must have network communication capability, whereby data can be streamed in near real-time over the Internet to a central data repository in order to operate autonomously. Finally, the magnetometer should be affordable so a wide group of users, which in addition to professional researchers could include radio amateurs and teachers, can participate in a large-scale magnetic observation network.

NPM, pictured in Fig. 1, is a networked, self-contained, turn-key, fluxgate magnetometer requiring zero maintenance and minimal skill to install. An overview of the instrument's design showing its constituent components appear in Fig. 2. Although it has applications in research or industry, it is currently being targeted as a teaching tool for science education. This is particularly relevant to the study of solar-terrestrial physics, which examines the effect of the Sun on the Earth's magnetic field, visually manifesting itself as the aurora. NPM is aptly suited as an aurora detector, whereby students can observe and analyze local perturbations in the Earth's magnetic field caused by substorm activity.

As of 2010, several NPMs have been distributed across Canada, particularly to sites in northern latitudes where magnetic fields show variation on the order or $100 \mathrm{nT}$ or more due to substorm activity. They are currently sending data to our AUTUMN (Athabasca University THEMIS UCLA Magnetometer Network) magnetic data repository. The data is accessible at our public data portal (http://autumn.athabascau.ca), and at its sister site that is geared towards science education (http://auroranet.org). Stations are optimally installed in the non-winter months, allowing operators to bury instruments in the ground.

Mainly through fieldwork performed by the University of California (Berkeley and Los Angeles) and the University of Calgary, the NASA THEMIS mission emplaced two magnetic networks known as the Ground Based Observatory (GBO) and Geomagnetic Event Observation Network by Students (GEONS). The latter involves a dozen 


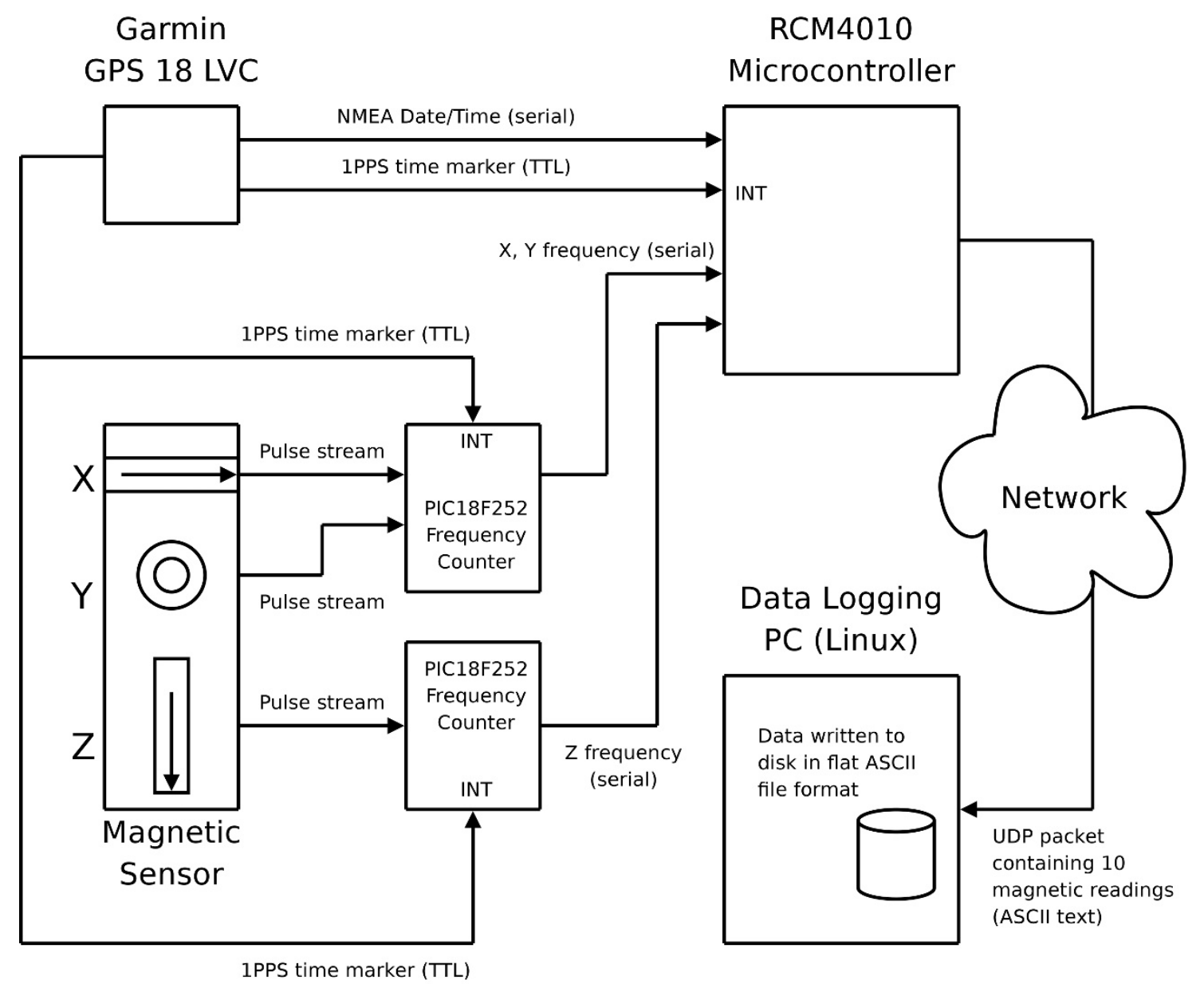

Fig. 2. Block diagram of the NPM networked magnetometer.

high schools across the United States as part the Education and Public Outreach (E/PO) effort of the current THEMIS mission to study the birth and evolution of substorms (Angelopoulos, 2008). Ten GEONS magnetometers were located at high schools within the United States, contributing magnetic data for the mission as well as educating students and the public about geomagnetism, space weather, the aurora and the THEMIS mission (Peticolas et al., 2008). Both GEONS and the THEMIS GBO network use the aforementioned UCLA THEMIS-GBO fluxgate magnetometer, each supported by a networked PC that transmits data in real-time data and also archives it locally to hard drive.

The GBO network couples the magnetometers with imagers, and forms an irregular grid of networked stations stretching from Newfoundland to Alaska. In general, GBO site locations were chosen for optimal optical coverage. The desired structure of the NPM instrument network is patterned after the THEMIS magnetometer network in which a network of autonomous, Internet-enabled instruments continuously feed data to a central data repository that can be browsed using its web-based data gateway. However, we have identified use of a support computer as a failure point (as well as expense and power draw) in networks based on GBO magnetometers, such as our own AUTUMN network. In addition, the need to have much greater spatial coverage forced us to consider low cost as an essential factor in our design.

We proceed to discuss NPM's components and method of construction, performance compared to current UCLA fluxgate magnetometers, and possible deployment strategies.

\subsection{Instrument design}

2.1.1 Magnetic sensors The heart of the NPM is its three Speake and Company FGM-3 digital fluxgate magnetometers (Speake \& Co. Llanfapley, 2010). These sensors use a proprietary design based on traditional fluxgate magnetometer technology. We have found these sensors to be sufficiently sensitive for use in geomagnetic research, but they are highly sensitive to temperature change. After considerable effort to resolve this issue, we settled on a design similar to the UCLA THEMIS-GBO magnetometers, which places the sensors in a tube buried vertically in the ground to provide thermal inertia. Three sensors located in the bottom of the tube are orthogonally oriented to measure the geomagnetic field strength in terms of local magnetic coordinates where $X_{M}$ is the component aligned with magnetic north, $Y_{M}$ with magnetic east, and $Z_{M}$ points vertically downward.

The FGM-3 emits a TTL-conformant (0-5V DC) digital pulse stream whose frequency is non-linearly proportional to the strength of the surrounding magnetic field, but approximately linear for small perturbations. A change in 
$1 \mathrm{~Hz}$ translates approximately into a $1 \mathrm{nT}$ difference. The FGM-3h variant offers an approximate 2.5-times boost in sensitivity at the expense of dynamic range, allowing the sensor to detect a 400 picotesla (pT) change in the magnetic field. The NPM uses the less sensitive FGM-3 to measure the relatively strong $B_{Z}$ component (as seen in high latitudes), while FGM-3h sensors are used for the $B_{X}$ and $B_{Y}$ components.

As mentioned, the FGM series of sensors are sensitive to ambient temperature. Therefore, it is crucial that FGM sensors be placed in thermally stable environments, preferably underground. Thermal isolation of the magnetic sensor probe has proven to be the best solution to counteract thermal biasing of the magnetic field data. Seasonal temperature changes appear in the data when viewed over a large time span. Baselining the data adequately compensates for this effect for the purposes of auroral research. This is achieved by taking the average of magnetic data from a recent magnetic quiet period and subtracting it from the immediate data, yielding a time series depicting magnetic field perturbations relative to the seasonal quiescent magnetic field. Similar correction is required even for observatorygrade magnetic detectors.

The NPM housing is a $1 \mathrm{~m}$ by $100 \mathrm{~mm}$ (sold as 4-inch) diameter ABS pipe. The top end (appearing to the left in Fig. 1) has a removable weatherproof threaded cap, while the bottom end appearing on the right is sealed. The tube is buried vertically in the ground so that approximately $15 \mathrm{~cm}$ of the top end of the tube lies exposed above ground. This allows the internal GPS antenna (the black disk to the left, pictured in Fig. 1) to receive adequate signal for generating a one-pulse-per-second (1 PPS) heartbeat or master timing signal. The top of the NPM housing is painted white to reflect solar radiation in order to reduce internal heat build-up. A polyurethane foam plug roughly $8 \mathrm{~cm}$ thick provides additional thermal isolation for the magnetic sensors located near the bottom of the tube.

A wood mounting board holding the electronics and the magnetic sensors sits firmly inside the tube when the top cap is screwed shut, and can be easily slid out the tube when the cap is removed. A weatherproof RJ-45 feed-through connector passing through to the top wall of the tube allows a standard Cat5 Ethernet cable to plug into the side of the NPM unit, allowing a secure, moisture-resistant connection.

The NPM design is considerably simpler and more compact than a similar research-grade magnetometer, such as the THEMIS GBO fluxgate magnetometer. The THEMIS GBO magnetometers that were distributed as part of the NASA THEMIS mission consisted of multiple components: $1.1 \mathrm{~m}$ long fluxgate magnetometer sensor tube, AC-powered magnetometer electronics unit, GPS antenna and receiver card, desktop PC and display, uninterruptable power supply (UPS), remote booting device, assorted cables, and data collection software (Russell et al., 2008). NPM was intentionally designed to encapsulate these components into a single unit in order to simplify installation. The operator of an NPM unit only needs to bury the instrument and provide power and Internet access. We chose to eliminate the desktop PC computer entirely because we felt was a major point of failure in terms of software and hard- ware reliability.

2.1.2 Frequency counters The FGM-3 and FGM-3h sensors both produce TTL pulse streams with frequencies ranging from the $10 \mathrm{~s}$ to $100 \mathrm{~s}$ of $\mathrm{kHz}$. We have found that the 8-bit "PIC" series of microcontrollers from Microchip, Inc. are ideal high-speed pulse counters, because, unlike many similar microcontrollers, PIC microcontrollers allow external clocking of some of their internal 16-bit registers, which can thus act as counters. The NPM uses twin PIC18F252 microcontrollers (Microchip Technology Inc., 2006), each having two externally clocked 16-bit counters. Because the output frequency of the magnetic sensors is sufficiently high to overflow the counters over the course of one second, frequency is measured by reading the stored counts added to the counter range multiplied by the number of timer overflows that occurred over the course of 1 second. The PIC counters return the resulting frequency measurement over a 9600-baud TTL-level serial data stream, which is easily read by the control microcontroller. As each PIC is able to count two pulse streams, one of the PICs returns the frequencies of sensors $X$ and $Y$, while the second PIC returns the frequency of sensor $Z$, leaving a spare channel.

In order to compute the pulse frequency, an accurate 1second time base must be provided as the master clock or heartbeat. The one pulse per second (1 PPS) signal from a GPS board is easy to obtain, as most OEM GPS boards provide this signal, which is accurate to $\pm 1 \mu \mathrm{S}$, making it an ideal time base for measuring the frequency of the magnetic sensor output signal. The master clock is implemented through an interrupt, with counter reset and transmission of frequency data as part of the interrupt service routine executed by the CPU (and thus not affecting the ability of the timing registers to count). Time and date information aligned to the leading edge of the 1 PPS signal is fed to the controlling microcontroller (MCU) module over a TTL serial link, and is encoded in industry-standard NMEA 0183 format (National Marine Electronics Association, 2002). We selected the Garmin GPS 18 LVC GPS engine (Garmin International Inc., 2005) for its compactness and simplicity. It is a $61 \mathrm{~mm}$ diameter by $19 \mathrm{~mm}$ thick disk containing an integrated receiver and antenna attached to a $5 \mathrm{~m}$ power/communication cable. The unit was configured to emit a 1 PPS pulse and the NMEA GPRMC sentence, thus providing the $1 \mathrm{~Hz}$ timing pulse and time stamps. Configuration settings are stored in the GPS unit's non-volatile memory.

2.1.3 Microcontroller NPM uses a Rabbit Semiconductor RCM4010 8-bit networked microcontroller module containing a $59.98 \mathrm{MHz}$ Rabbit $4000 \mathrm{CPU}$ with $512 \mathrm{kB}$ of SRAM and $512 \mathrm{kB}$ of non-volatile FLASH program storage (Digi International Inc., 2010). The pulse counting PICs and additional electronics are integrated on a customdesigned printed circuit board (PCB) that provides on-board regulated 3.3 and $5 \mathrm{DC}$ voltage, plug in dual inline package (DIP) sockets for mounting DIP components, and a plug-in header on which to mount the Rabbit RCM4010 MCU core module.

Previous experience with Rabbit 2000 microcontroller modules in networked applications (Schofield and Naylor, 2007), showing them to be capable of reliable internetwork 
communication, led to the decision to port the project from an initial design based on a Microchip "dsPIC" microcontroller board to the Rabbit platform. In the course of a few weeks, we were able to convert the needed part of PICbased source code to Rabbit Semiconductor's Dynamic C (version 10.23).

The NPM control software centers around an interrupt service routine (ISR) triggered by a 1 PPS signal from the GPS. The 1 PPS signal alerts the software to read the current magnetometer sensor frequencies from the PIC pulse counters. Then, the GPS unit's date-time string formatted as a NMEA 0183 GPRMC sentence is read by the Rabbit MCU. Frequency and time information are buffered until ten samples are collected and then transmitted to a remote data collection server over the UDP datagram network socket (Postel, 1980). 10 second data blocks are 440 bytes in size. This size was selected in order to avoid fragmenting the data across several UDP packets and to use the space provided in a default 512 byte UDP packet in an efficient manner.

The UDP protocol used for data transmission is relatively simple and has little overhead, thus it lends itself to use on small embedded appliances such as NPM. However, UDP transmission does not guarantee delivery of transmitted packets, nor the order in which they are received. In situations where an NPM unit must send data that must cross multiple networks (internetworking) as opposed to a local area network (LAN) environment, packet loss is a distinct possibility, particularly where network quality of service is questionable. For this reason, onboard logging onto a nonvolatile flash memory device is desirable for NPM units that require an assured record of their data. A separate NPM unit based around the Rabbit 4300 core module that uses mini SD memory was successfully tested. Buffered data is written to the mini SD card formatted with a FAT file system. This is done only every 60 seconds in order to minimize write cycles, thus extending the lifespan of the storage media. An additional advantage of this memory-based storage is that in principle a device could be developed that operated without being attached to a network, with an operator retrieving the data manually as needed or dictated by the storage capacity.

To simplify installation, the NPM is a single integrated unit containing the GPS, magnetic sensors and control electronics. It receives power and network over a Cat5-E Ethernet cable configured as a Power-over-Ethernet (PoE) cable, where two otherwise unused twisted pairs carry DC voltage and ground. A PoE cable can carry power and communications up to $100 \mathrm{~m}$, nominally at data rates of $100 \mathrm{Mbit} / \mathrm{s}$. In tests, we achieved best results with PoE cable lengths up to $75 \mathrm{~m}$, beyond which Ethernet speeds needed to be reduced to $10 \mathrm{Mbit} / \mathrm{s}$.

Since the unit is small, costs of network deployment can be minimized by sending it to the cooperating install site rather than making a field trip. NPM was designed with simplicity of installation in mind, requiring only a few manual tools. A posthole digger is used to make a $\sim 1 \mathrm{~m}$ deep hole into which the unit is placed vertically and secured with sand. The NPM must be placed in an area free of pedestrian or vehicular traffic, far from large magnetic ob- jects such as electric motors and motor vehicles. The top of the NPM tube remains above ground and must have a clear view of the sky so that GPS signals may be received. Once the NPM unit is buried in an acceptable location and aligned to magnetic north (easily done using a handheld compass), the operator connects power and network into a D-Link DWL-P200 PoE base unit (D-Link Corporation, 2004) and runs a Cat5-E Ethernet cable from the base unit to the NPM. The microcontroller is configured in firmware to search for its network configuration using the dynamic host configuration protocol (DHCP).

When the magnetometer controller is powered up, data collection begins upon receipt of the 1 PPS signal. This occurs when the GPS unit calculates a fix on the minimum required number of satellites. On a cold start, this can take about a minute with the particular Garmin GPS module used by NPM. Afterwards, packets of ten data points are transmitted to our data logging server every ten seconds over a pre-defined range of network ports. It is necessary that the magnetometer site's firewall, if one is in use, be configured to allow outgoing network traffic over these ports.

\section{Field Testing and Performance}

Instrument tests that started in early 2008 are still ongoing at the Athabasca University Geophysical Observatory (AUGO). AUGO is located on the Athabasca University campus, on the outskirts of the town of Athabasca, Alberta, geodetic latitude 54.71 north, 113.31 west (CGM coordinates: 61.88 north, 302.22 longitude). This falls near the southern boundary of the northern auroral zone, the region where auroral activity is most visible in the northern hemisphere. Over North America, this latitudinally confined belt extends across Alaska, Western Canada, Northern Quebec and Ontario. At auroral latitudes, the $B_{X}$ and $B_{Z}$ components tend to dominate the signal, being driven by the east/west electrojet in the ionosphere. At subauroral latitudes, the $B_{Y}$ component predominates, and is the result of field aligned currents.

As shown in Fig. 3, the geomagnetic field at Athabasca on January 12, 2009 was particularly quiet. The data is dominated by the daily variation $\left(S_{\mathrm{q}}\right)$. Quiet conditions are ideal for testing the sensitivity and accuracy of the instrument. The NPM was tested against a calibrated $1-\mathrm{Hz}$, 9.5 pT SMALL fluxgate magnetometer located at AUGO. This UCLA-built instrument was originally designed for the Sino-Magnetic Array at Low Latitudes (SMALL) survey, a project to build a modern magnetometer array across China (Gao et al., 2000). Data from the SMALL magnetometer is represented in $\mathrm{nT}$, with NPM data converted to these units using procedures similar to those described below. Figure 3 shows a clear correlation between the calibrated SMALL data, appearing as the lower trace in each strip chart, and the NPM data, appearing as the upper trace.

Both magnetometers sample the magnetic field at $1 \mathrm{~Hz}$ and are synchronized to GPS timing, so no time base correction on the data is required. In order to correct for visible curvature in the original NPM data, second order polynomial curves were fitted to the NPM data. Subtracting the fit curve from the original data yields a flatter data set. Given 
Athabasca, Alberta, January 12, 2009
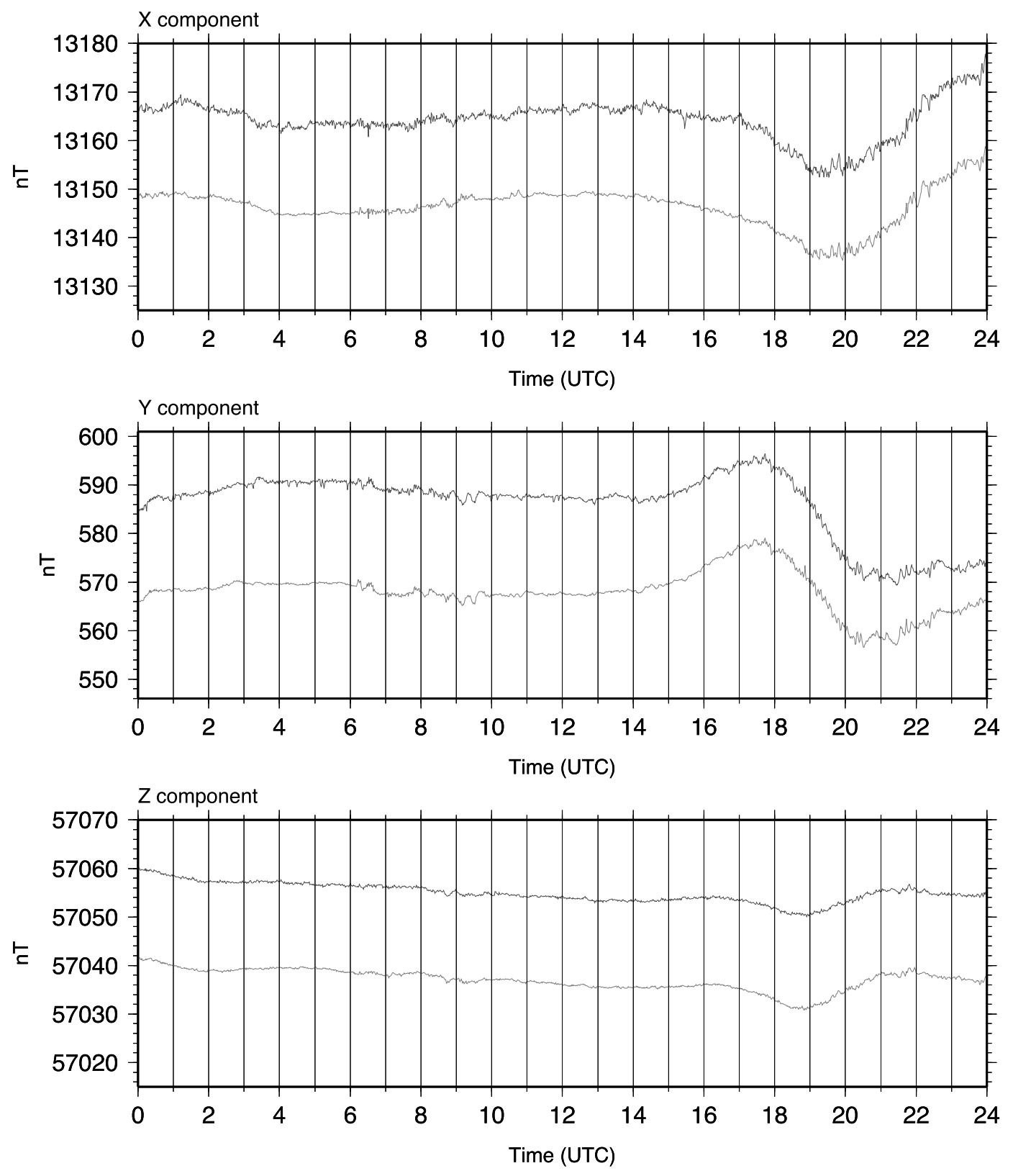

Fig. 3. Magnetograms showing $B_{X}, B_{Y}$, and $B_{Z}$ components from January 12, 2009 at Athabasca, Alberta, Canada. The lower trace in each chart shows data gathered from a calibrated SMALL $1 \mathrm{~Hz}$ fluxgate magnetometer. The upper trace shows data from a NPM unit that has been offset by 18 nT to enhance readability. The bulge appearing between 14:00 and 00:00 UT is due to diurnal effects on the magnetic field.

that the instrument is a technology demonstrator, the sensor mounting hardware consists of a wooden plank with orthogonally oriented grooves for the sensors to sit in and fastened with plastic cable ties. We attribute some very small differences to sensor misalignment. In principle, a rotation of axes could be done mathematically to correct this. What we regard as more important is that small perturbations show a high degree of similarity between the NPM and SMALL instruments.

Figure 4 shows data gathered on a magnetically active day. On January 26, 2009 magnetic perturbations of over $100 \mathrm{nT}$ were detected in all three magnetic components. At 00:30 UT, a positive spike appears in the $B_{Y}$ component, probably resulting from overhead upward field-aligned cur- rent. Towards midnight local time (07:00 UT), the $B_{Y}$ component shows a similar positive spike. Around 13:00 UT, a prominent negative bay appears in the $B_{X}$ component, suggesting detection of nearby westward ionospheric currents (electrojet). An increase in the $B_{Z}$ component (to less negative values) also suggests proximity to Athabasca, and a negative $B_{Y}$ perturbation suggests downward field-aligned current to the north. Experience has shown that such perturbations at Athabasca generally indicate that a visible aurora is present in the northern sky, so that the NPM can be claimed to be an "aurora detector". We now proceed to make a detailed comparison between NPM results and those of other instruments, showing the value of NPM for scientific studies. 
Athabasca, Alberta, January 26, 2009
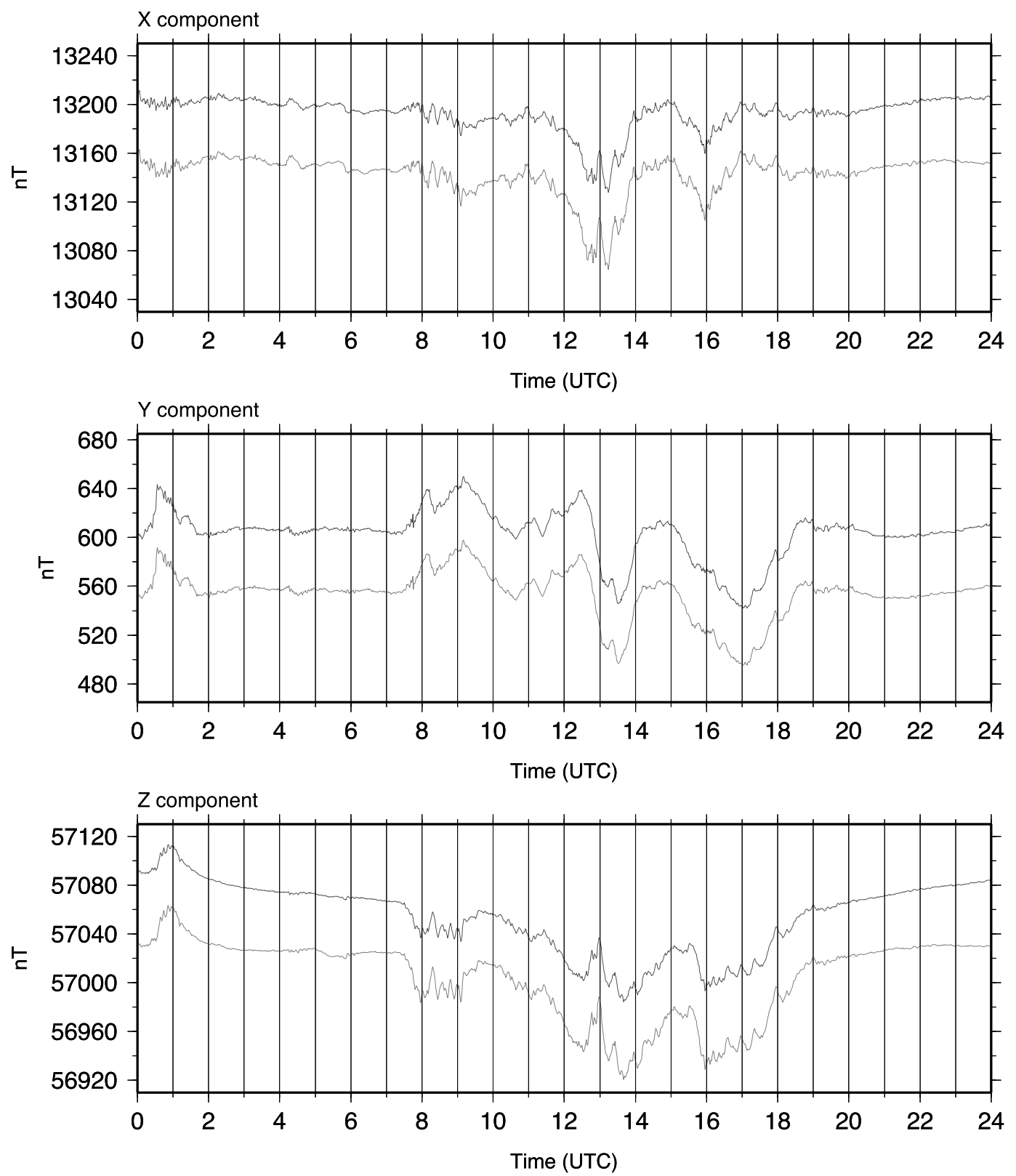

Fig. 4. Magnetic data gathered from NPM from January 26, 2009 at Athabasca, Alberta, Canada. NPM data appears in the upper trace and the calibrated SMALL $1 \mathrm{~Hz}$ fluxgate magnetometer is shown in the lower trace. The NPM data is offset by $50 \mathrm{nT}$ to enhance readability.

\section{Pulsation Event of September 4, 2010}

Routine use of our web-based NPM data display facility (http://auroranet.org) allowed identification of a period on September 4, 2010 when moderate amplitude Pc 5 waves appeared to grow and decay within an envelope (see Fig. 5) as observed at Athabasca and Grande Prairie, Alberta. Other ground stations, including those in the midnight sector, and the Provisional $A_{\mathrm{L}}$ index showed no sudden $B_{X}$ component drops which could be associated with substorms. Both the THEMIS and Provisional $A_{\mathrm{E}}$ indices grew gently from low values to approximately $100 \mathrm{nT}$ after 12 UT. This is consistent with a low solar wind speed and density, and only a moderate negative $B_{Z}$ component after 12 UT as shown in Fig. 5. Initiation of the pulsation event seems to have been simultaneous with an approximately 5 min decrease by about $30 \mathrm{~km} / \mathrm{s}$ in the solar wind speed, followed by a $15 \mathrm{~km} / \mathrm{s}$ increase at 13:20 UT. At this time, $B_{Z}$ also became negative, although never exceeding $2 \mathrm{nT}$ in magnitude during the event. The pulsation amplitude subsided starting at approximately 15:30 UT when the $B_{Z}$ rose to about $-1 \mathrm{nT}$, and stopped when the IMF $B_{Z}$ turned positive. It would appear that the most important factor controlling the pulsations was the IMF $B_{Z}$ component. Singer (1982) gave examples of Pc 5 pulsations observed in space in very quiet solar wind conditions. Recent thought on the origin of ULF waves (Kivelson, 2006) has mainly focused on field-line resonances or origin through excitation on the flanks of the magnetosphere and usually under more active solar wind conditions, notably of higher speed. In this paper, which focuses on instrumental technique, we do not 


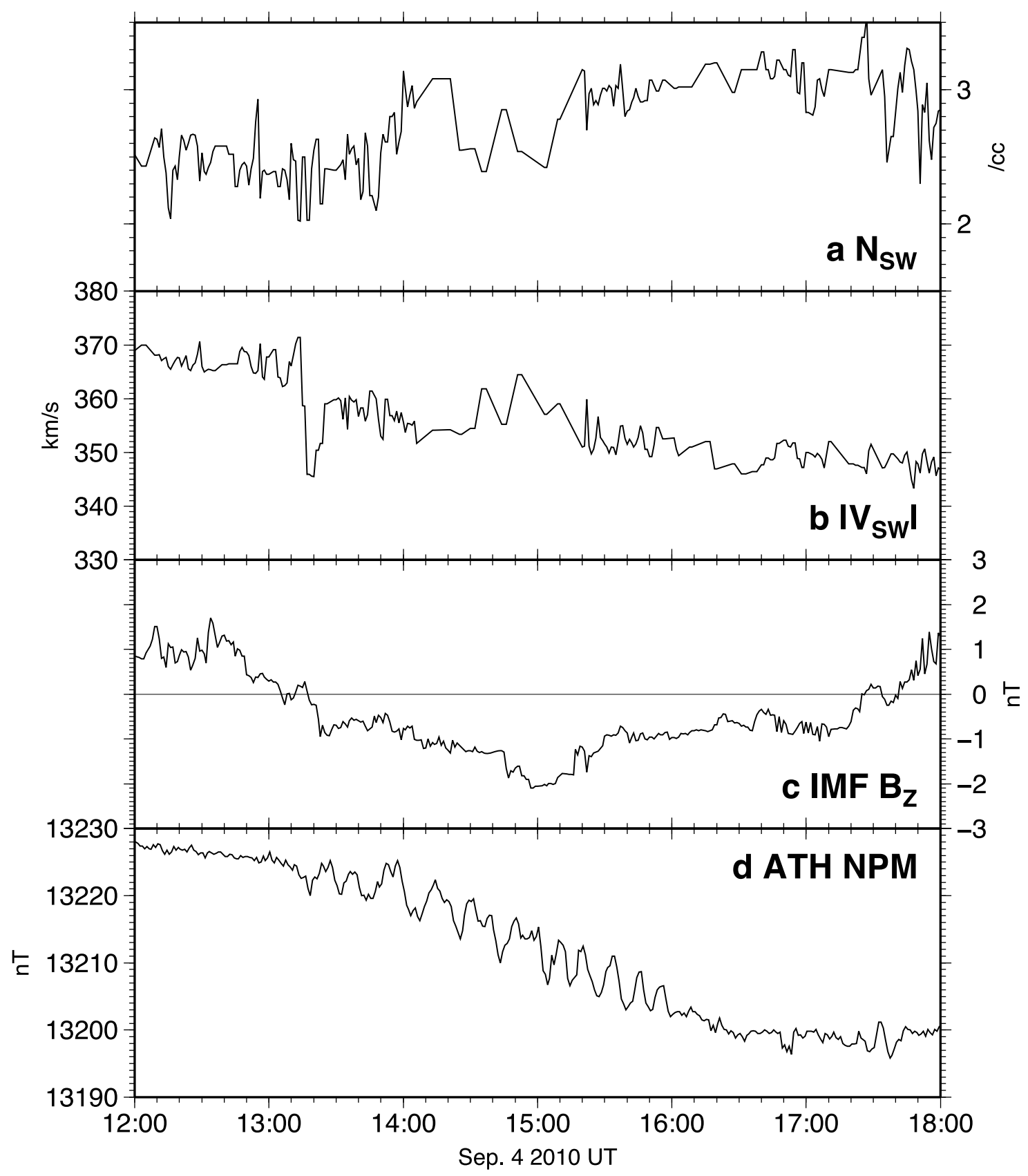

Fig. 5. (a) Propagated solar wind proton density per cubic centimeter. (b) Propagated solar wind speed. (c) Propagated IMF $B_{Z}$ component. (d) Athabasca NPM magnetic north component calibrated data, showing detection of a pulsation event. Solar wind data is from the OMNI database.

undertake detailed analysis of origin of the observed event, but do note below that an association with field-line resonance is not likely, nor is an origin of the wave power on the flank.

\subsection{Ground observations}

The NPM magnetometers in Athabasca, Alberta (ATH) and Grande Prairie, Alberta (GPR), have corresponding more northerly sites in the CANOPUS/CARISMA/THEMIS network at Fort Smith, Alberta (SMI) and Fort Simpson (SIM), Northwest Territories, respectively. Station locations are displayed below in Subsection 4.3 (see Fig. 9). The northward component of the magnetic field at these stations is shown in Fig. 6, although raw counts are shown for Grande Prairie. Comparison of the GPR and ATH signals shows no discernable phase shift, nor do SIM and SMI. On the other hand, comparison of ATH to SMI, and GPR to SIM, shows that the more northerly stations have a signal lag with respect to the corresponding more southerly station. This immediately suggests a northward propagating signal, since phase fronts in that case would cross stations at the same magnetic latitude essentially simultaneously, but be delayed at the more northerly station of a pair displaced in magnetic latitude. For comparison, the more southerly station of Red Deer (RED) also has data shown. At this station the amplitude is lower than at ATH, approximately $300 \mathrm{~km}$ to its north, and phase shift is very small. The period of the pulsations is approximately 10 minutes $(600 \mathrm{~s})$ as observed at all stations shown, making them of the low frequency Pc 5 pulsation class (Samson, 1991). The nearly sinusoidal 


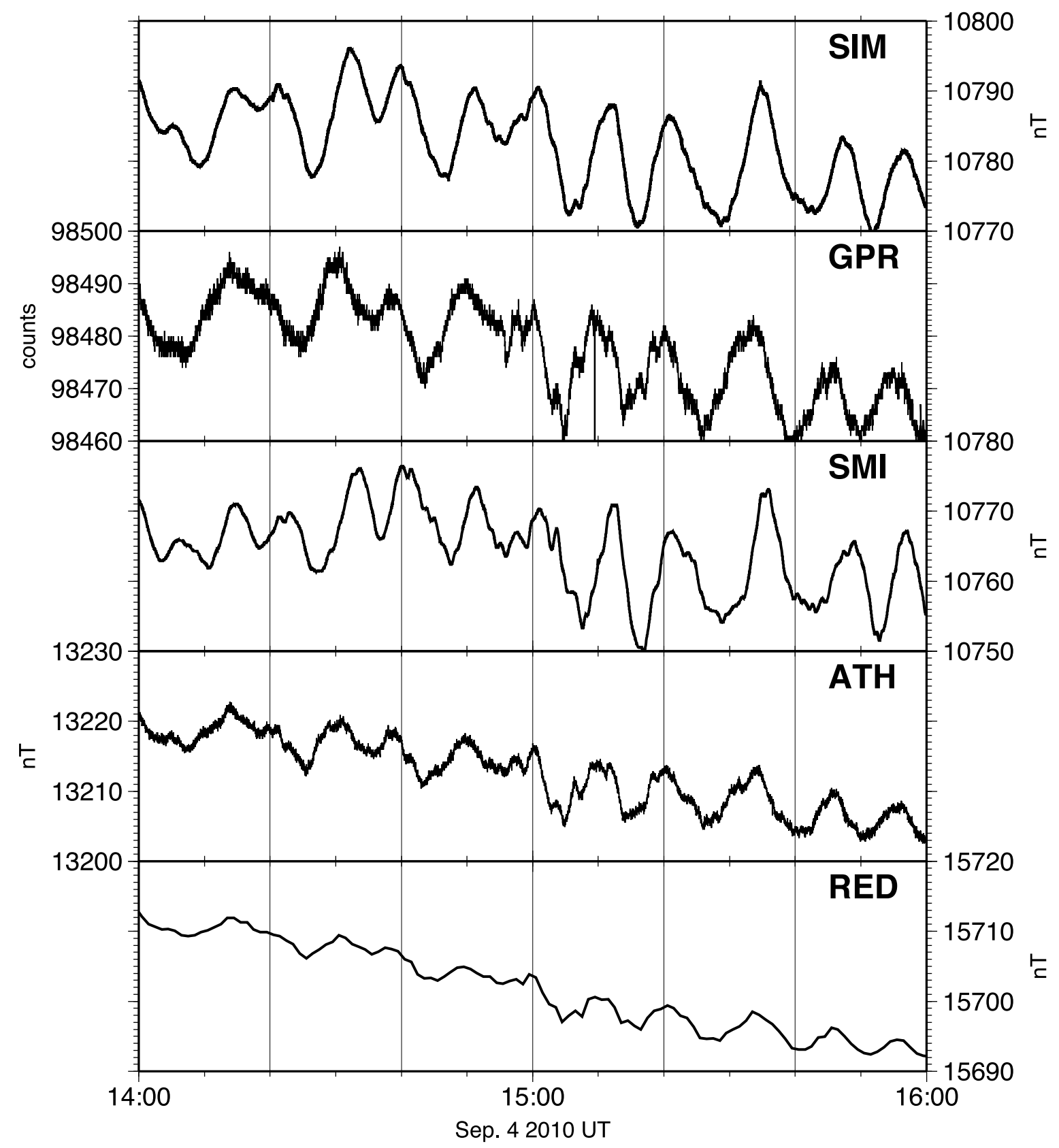

Fig. 6. Magnetic northward components from subauroral AUTUMN site RED (Red Deer), NPM sites ATH (Athabasca) and GPR (Grande Prairie), and corresponding auroral zone THEMIS network sites SMI (Fort Smith) and SIM (Fort Simpson). An extremely high degree of coherence is clear, with the auroral zone signals slightly delayed in time compared to the subauroral signals. GPR data is shown with raw counts in order to show that the resolution of NPM, although inferior to that of fluxgates, is suited for studying large-amplitude ULF pulsations. For other sites the scale in nT is identical. The NPM instruments have an intrinsic noise level of order $1 \mathrm{nT}$, higher than that of the fluxgate instruments at RED, SIM, and SMI.

nature of the variations led us to investigate their spectra, including to what degree the low-cost instruments under discussion could be used to study spectra. We will now initially discuss characteristics of the signals including quality of detection; then propagation and mapping.

The first $7100 \mathrm{~s}$ (nearly two hours) of data from Fig. 6 had their average value removed, were windowed with a Hann (cosine taper) function, and the FFT was taken using the variable length FFTW algorithm (Frigo and Johnson, 2005). The one-second cadence data resulted in a maximum (Nyquist) frequency of $0.5 \mathrm{~Hz}$, and this length of data resulted in a spectral spacing of $0.141 \mathrm{mHz}$. Discrete peaks were seen in the amplitudes of the spectra at all stations at frequencies below $10 \mathrm{mHz}$, as shown in Fig. 7. The strongest peak is centered at $1.6 \mathrm{mHz}$, which corresponds to $625 \mathrm{~s}$ period, very near that estimated for the pulsations in the time domain plots. Subsidiary peaks appear to be at the two harmonics of this value. All instruments also indicated a broad peak at about $5.5 \mathrm{mHz}$. The spectra from the ATH and GRP sites are consistent with those from the standard observatory at Meanook (MEA), $18 \mathrm{~km}$ south of Athabasca, and high quality fluxgates at SIM, SMI, and INU (AUTUMN/THEMIS fluxgate at Inuvik). No spurious spectral peaks were noted in the NPMs, although it is clear from the noise level apparent in Fig. 6 that very lowamplitude pulsations would not be able to be detected with 


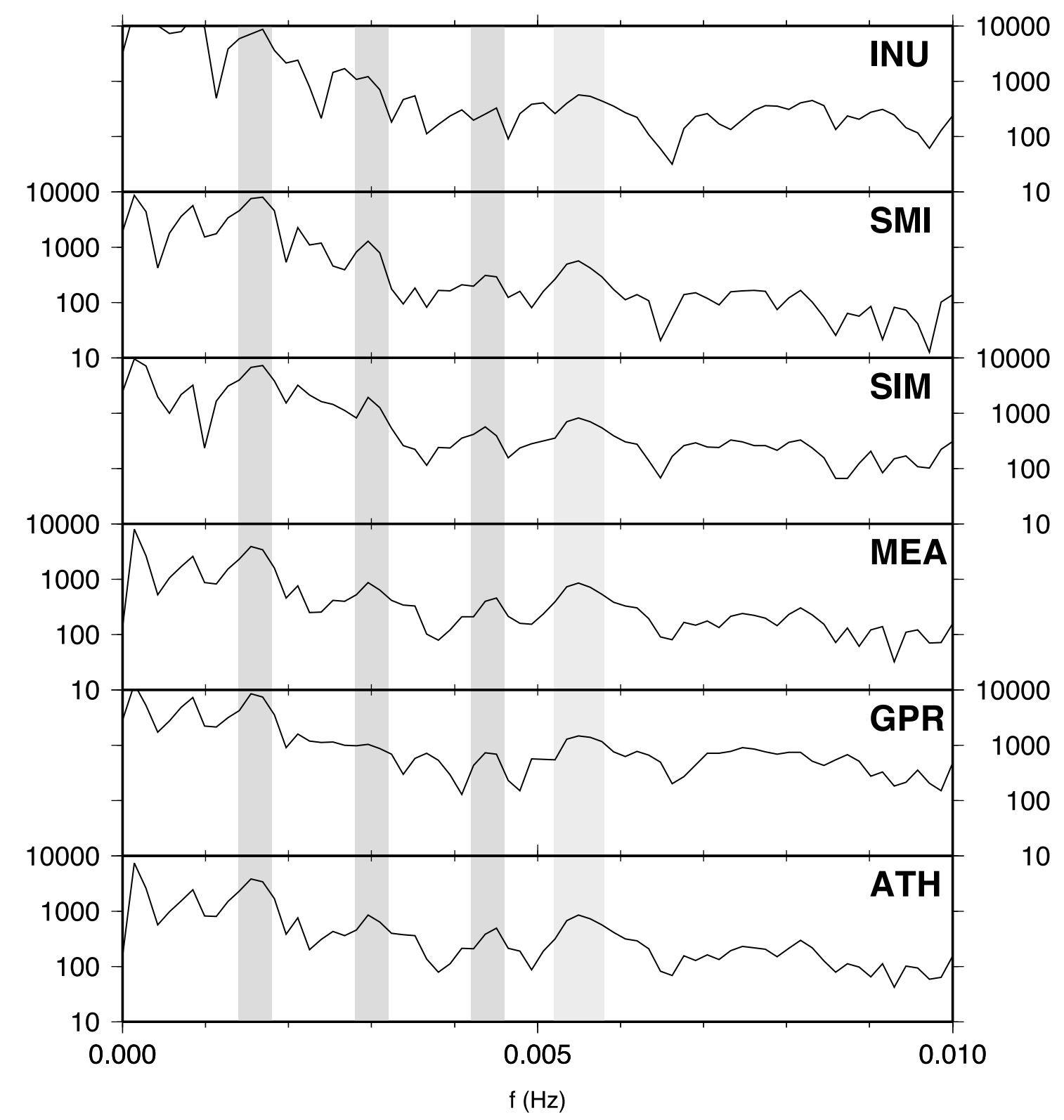

Fig. 7. Amplitudes (in nT/Hz) of the Fourier transform of the magnetic northward component at subauroral NPM sites whose data was shown in Fig. 6. Additionally, data from the federal government observatory $18 \mathrm{~km} \mathrm{~S}$ of ATH at Meanook (MEA) and Inuvik (INU), whose auroral zone position may be seen in Fig. 9, are shown. Gray bands indicate frequencies near 0.0015, 0.003, and $0.0045 \mathrm{~Hz}$, which appear to be harmonically related. A wider spectral peak near $0.0055 \mathrm{~Hz}$ is indicated by light gray shading. The same frequencies are detected at all stations, including NPM stations ATH and GPR. Further, MEA is an observatory class instrument $18 \mathrm{~km}$ south of the ATH NPM, with an almost identical spectrum. The vertical scale is logarithmic over three decades.

them.

Propagation toward the north was inferred from the time series, and a lagged correlation was done to determine the speed of propagation. This may be written (Box and Jenkins, 1976) as

$$
\rho_{x y}(k)=\frac{E\left[\left(x_{t-k}-\mu_{x}\right)\left(y_{t}-\mu_{y}\right)\right]}{\sigma_{x} \sigma_{y}},
$$

where $\rho_{x y}(k)$ is the correlation coefficient at lag $k, E$ is the expectation value, and $x$ and $y$ are the data time series of the same length and spacing, with internal standard deviations $\sigma_{x}$ and $\sigma_{y}$ respectively.

For sums over discrete data with index $i$, this may be written as

$$
\rho_{x y}(k)=\frac{\sum_{i}\left[\left(x_{i-k}-\mu_{x}\right)\left(y_{i}-\mu_{y}\right)\right]}{\sqrt{\sum_{i}\left(x_{i-k}-\mu_{x}\right)^{2}} \sqrt{\sum_{i}\left(y_{i}-\mu_{y}\right)^{2}}},
$$

and implemented in a straightforward way. Cross correlations for 3190 values starting at 14:00 UT (i.e. nearly an hour of data) between the respective north-south station pairs ATH-SMI and GPR-SIM are shown in Fig. 8. Peaks in these correlations for values less than $200 \mathrm{~s}$ lag are due to the similar portion of the wave train passing the stations, and the large value indicates the strong similarity of the signal after propagation, to the signal observed at the more southerly station of the pair. In a stationary time series with 


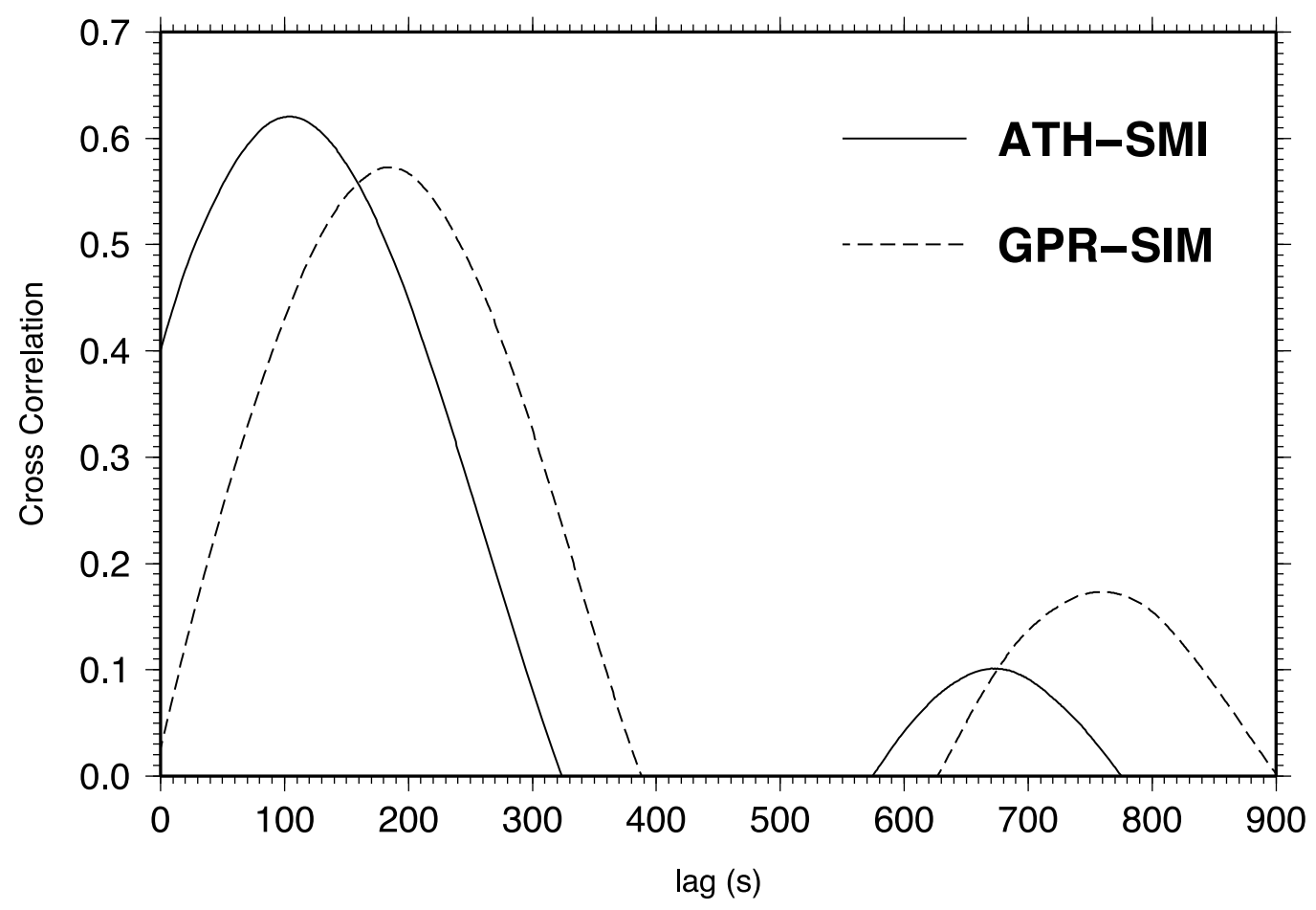

Fig. 8. Normalized cross-correlations between ATH and SMI (solid line) and GPR and SIM (dashed line).

strong periodicity, secondary peaks would be nearly as high as the initial peaks. In this case, no detrending was done to make the time series stationary, and the secondary peaks near a delay of $700 \mathrm{~s}$ are smaller than the primary peaks. Nevertheless the spacing of roughly 600 s to the secondary peaks is consistent with the period determined by two methods previously. The main result from the cross-correlation study is that there is a delay of about $100 \mathrm{~s}$ between ATH and SMI, and of about $180 \mathrm{~s}$ between GPR and SIM. As may be seen in Fig. 9, the ratio of separation of these site pairs is not this large. This implies that the wave phase speed near Earth's surface decreased with latitude.

\subsection{Mapping to the magnetosphere}

Due to quiet conditions prevailing, and the small amplitude of the pulsations compared to the background magnetic field, it is reasonable to expect that empirical magnetospheric models would provide a good indication of the mapping of the pulsations into space. Mappings from the ground stations discussed using the T89 model (Tsyganenko, 1989) are shown in Fig. 9. This model is based on averaging magnetic field observations made in space by several spacecraft prior to 1989 . Also shown is the Petrinec-Russell (1996) magnetosphere boundary, similarly based on empirical fits to readily identifiable magnetopause boundary crossings by spacecraft. The IMF $B_{Z}=-1 \mathrm{nT}$ and $P=0.7 \mathrm{nPa}$ parameters used are not unusual in the solar wind, so that the plotted boundary is expected to conform well to that during this event. Also shown are the approximate range of plasmapause locations for the dawn sector for quiet conditions (O'Brien and Moldwin, 2003). Once more, this is derived from empirical fits to a readily identifiable boundary, but with a smaller dataset having been used than in the magnetic field and boundary models, the range of possible values is larger. It is seen that the ATH and GPR stations map to near the plasmapause, while the magnetopause is remote from the mapping location and in the direction toward which the pulsations propagate. Data from other AUTUMN chain stations south of ATH, such as RED, indicate a rapidly decreasing amplitude of the pulsations at those locations, which would map to near or inside the plasmapause. This pulsation event appears to have had waves originating at the plasmapause, closely associated with the time during which the IMF $B_{Z}$ was negative. This suggests an association with reconnection-induced changes in the inner magnetosphere. The present study is not able to indicate more. However, it shows that the deployment of our low-cost magnetometers allowed the identification of a type of pulsational behavior of which we were previously unaware, and apparently not yet documented.

We suggest that further study of such events is merited. Further deployment of large arrays, enabled by low-cost magnetometers, would be an effective way of furthering studies of such pulsations and other phenomena.

\section{Substorm and Space Weather Event of April 5, 2010}

The question of the optimal spacing of magnetometers was a moot point when the instruments were relatively expensive and difficult to install. It has been widely claimed that a spacing of less than approximately the height of the ionosphere is not useful since magnetic signals should not vary on much smaller scales. In general the spacing of existing magnetometers is much greater than the ca. $100 \mathrm{~km}$ separation this criterion would imply, and the matter has not been put to the test. Here we describe an auroral event in which a small magnetometer spacing revealed significant gradients in magnetic field. 

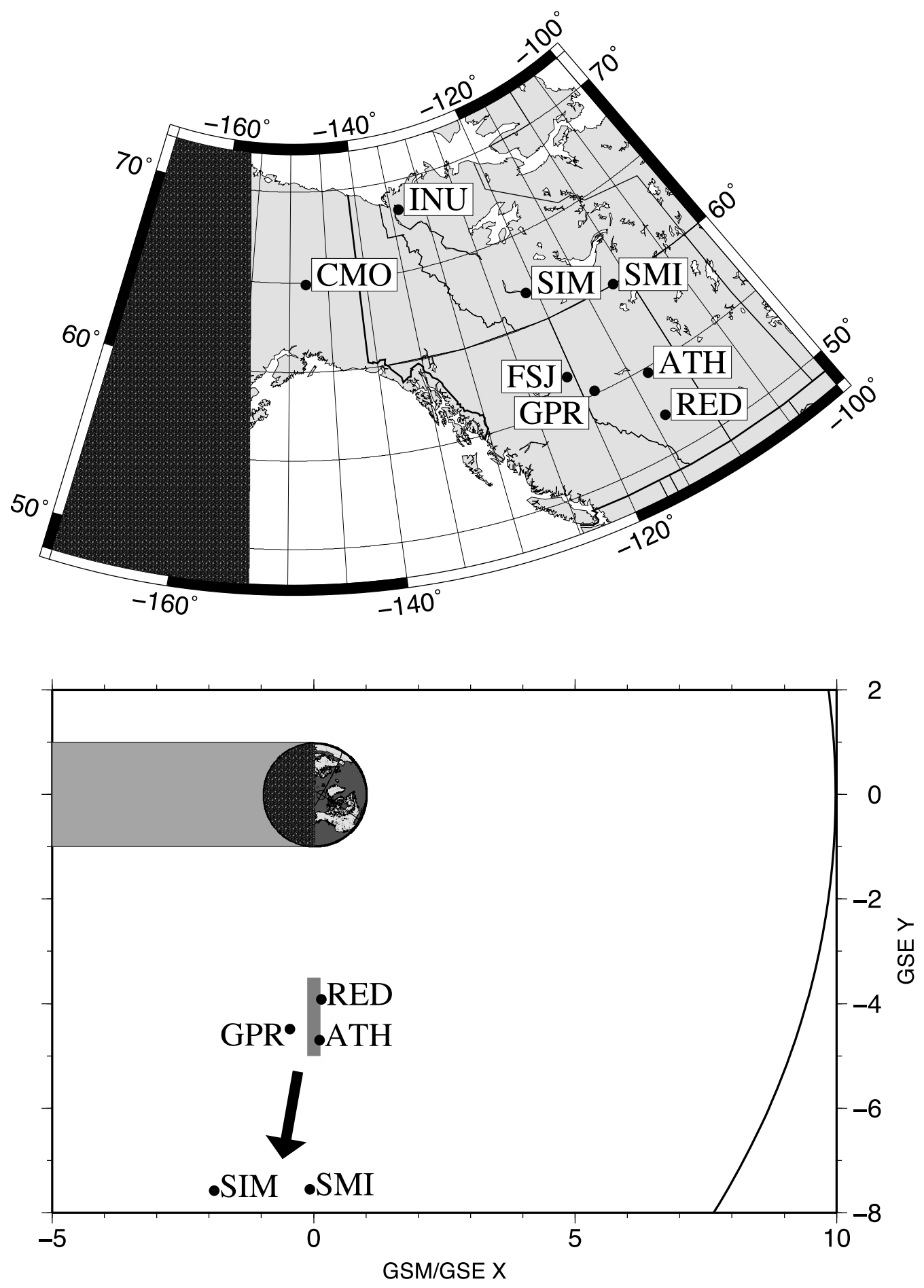

Fig. 9. GSE Equatorial plane mapping, using the Tsyganenko 89 model, of sites having detected the pulsations. The mapping of INU to approximately $(-11,-13) R_{\mathrm{E}}$ is outside the region shown in the lower panel, but still inside the magnetopause. The normal range of plasmapause location in the dawn sector under quiet solar wind conditions is shown by a gray vertical bar centered near GSE $X=0, Y=-4$. The inferred radially outward direction of motion of pulsation phase in this local time sector is shown by an arrow. Site locations in western Canada/USA are shown in the top panel.

\subsection{Comments on density of coverage}

Auroral currents in the ionosphere often flow in electrojets (Baumjohann and Treumann, 1997, pp. 89-90) basically along the magnetic east-west direction; predominantly eastward in the evening sector, westward in the morning sector, and often with westward current north of eastward current west of midnight (late evening sector). Use of Ampere's Law in such a simple situation leads to the conclusion that a long westward electrojet has a negative $X$ component at ground level near the center of its latitudinal extent. Bearing in mind that the $Z$ component is positive downward, a simple westward electrojet produces a negative perturbation in this component to its south, a positive perturbation to its north, and no $Z$ perturbation at its latitudinal center. The $X$ component changes rapidly near the borders if they are sharply defined, and the $Z$ component rapidly near the cen- 


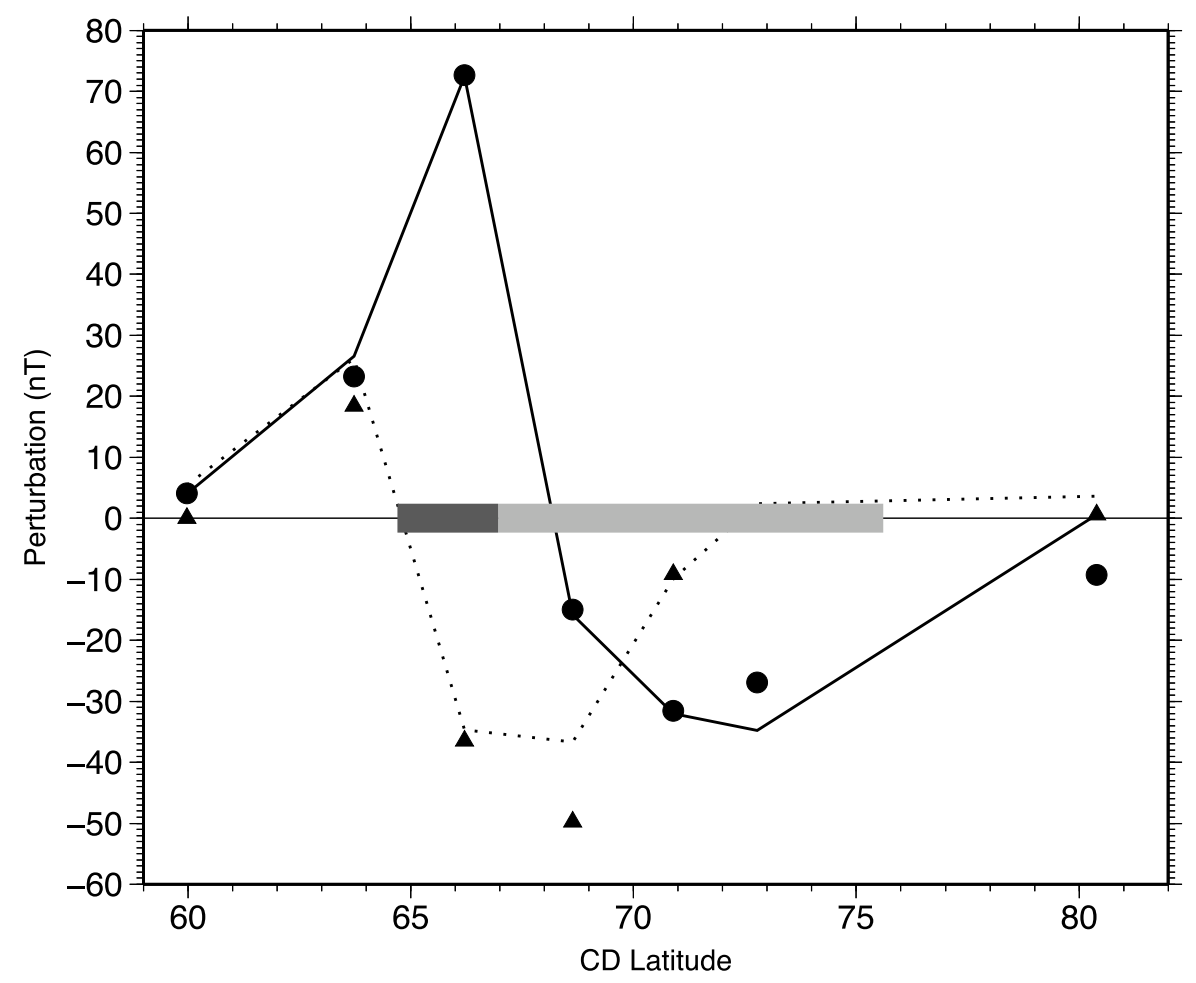

Fig. 10. $\quad X$ (black circles) and $Z$ (triangles) component magnetic perturbations from the central Canadian CANOPUS Chain at 3:30 UT on Feb. 22 1997. Corresponding model output is shown by solid and dotted lines. The dark gray region on the $X$ axis corresponds to a latitudinally restrained region of eastward electrojet (ionospheric electric current flow), and the light gray region to a broad westward electrojet poleward of it. There is very good agreement between the data and the model result (note one $Z$ point at $-50 \mathrm{nT}$ which has the most disagreement). Large gradients in both magnetic components arise near the interface of the electrojets at 67 degrees of $\mathrm{CD}$ (centered dipole) latitude.

ter in general. If the electrojet is at near-constant latitude, it develops little $Y$ component. This simple situation, and the analogous eastward electrojet, is illustrated from model calculations by Kisabeth (1979). Figure 10 shows a similar, more complex model of an eastward electrojet with a wider westward electrojet north of it, from the evening sector during the growth phase of an auroral event on Feb. 22, 1997.

In this example, the spacing of stations near the auroral oval was 2 to 3 degrees, i.e. roughly $250 \mathrm{~km}$. The model appears to have captured the essential features of the electrojet situation, especially given the good match to data. However, the maximum in $X$ due to the eastward electrojet is represented by only one point, and the gradient near the electrojet interface only by two points. Clearly, extra stations would not be redundant, and could sharpen the resolution in the interface region.

In specific auroral events, there would be two advantages to wide and dense coverage which low-cost magnetometers allow. Stations filling an area allow detection of events where they might not have been detected without that coverage. Runov et al. (2011) examine the timing of a dipolarization front observed by the THEMIS spacecraft relative to a minor current intensification observed from the ground. The latter was extremely localized and detected clearly at only one station (Yellowknife) which was not part of the THEMIS ground network. Proper study of the event benefitted from the de facto increase in density by adding this station. Placement of more magnetic instruments enhances the precision with which timing studies can be done. The second advantage is that details of the auroral currents can be discussed with higher spatial resolution if densely placed stations exist where this resolution is needed.

\subsection{Localized auroral currents}

Since we are in the evaluation phase of our project, we do not yet have a dense network deployed. However, the major auroral event of April 5, 2010 (Connors et al., 2011) had large signals detected in western Canada, including at the NPM site at Grande Prairie, Alberta. The STEP Polar Network site at Fort St. John, British Columbia, is $166 \mathrm{~km}$ NW of Grande Prairie (see Fig. 9) and houses a standard Narod fluxgate magnetometer. Compared to most other existing site pairs, these sites are relatively close together and suited to investigating whether closely spaced sites are useful during an auroral event. A comparison of the differences in observed signals during this large event is best based on cross-calibration during the event itself. An auroral camera was operating at Athabasca (AUGO observatory, equivalent to the magnetic station ATH) during the event with FSJ and GPR on the edge of the field of view. We can thus compare inferences based on both optical and magnetic data.

The magnetic perturbations at Grande Prairie (GPR), Fort St. John (FSJ), and the Alaskan station of College (CMO) during the most active part of the event are shown in Fig. 11. Connors et al. (2011) identified the shock onset corresponding to the start of the major auroral event as being at 08:25 at the nose of the magnetosphere, based on Geotail spacecraft data. The ground $X$ component started to decrease at all stations at 08:27 to the one-minute accuracy shown. The next identified event was a dipolarization at GOES 11 at 


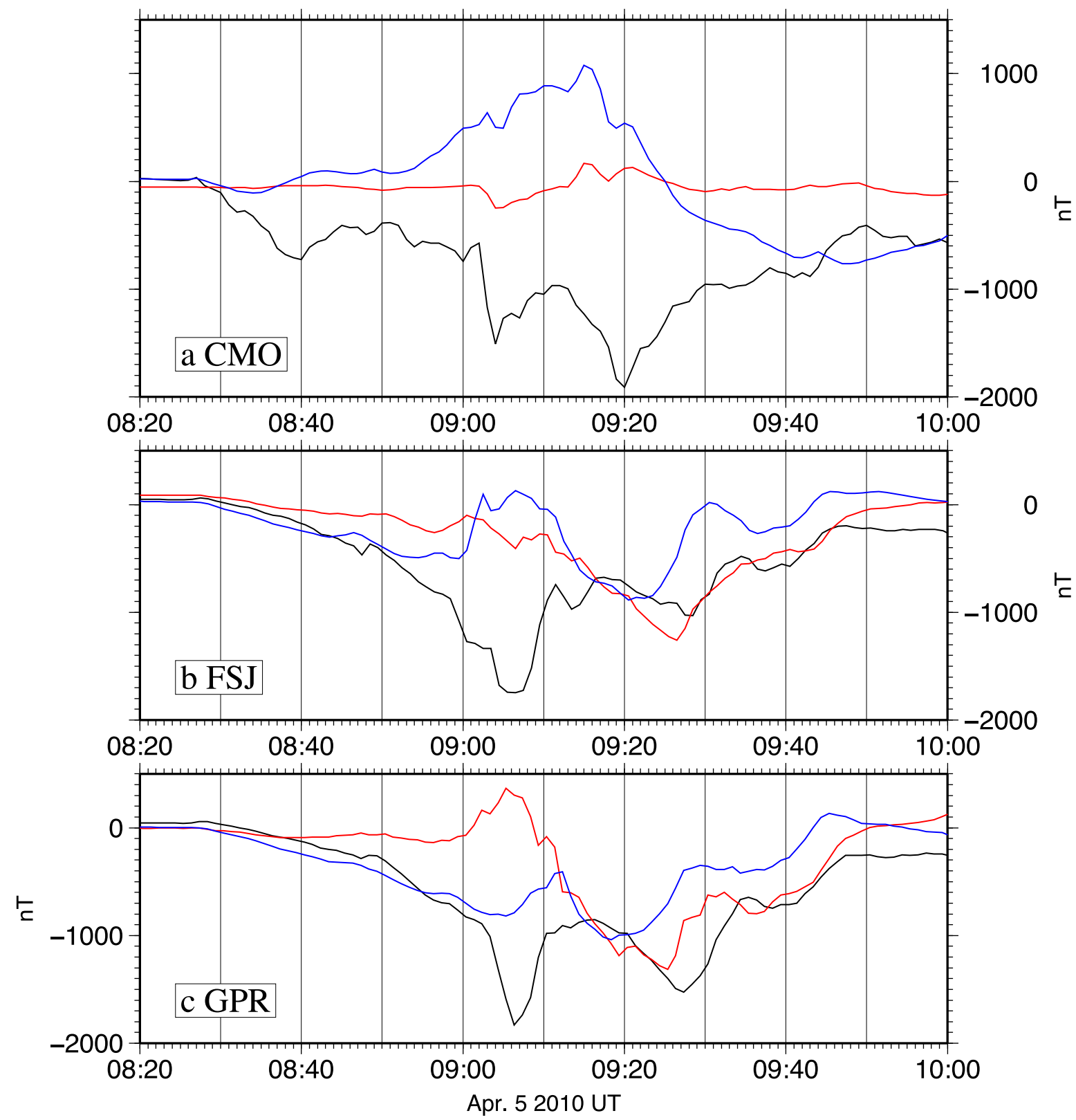

Fig. 11. $X$ (black lines), $Y$ (red lines), $Z$ (blue lines) magnetic perturbations at (a) College (CMO), (b) Fort St. John (FSJ), and (c) Grande Prairie (GPR) on April 5 2010. Panels (b) and (c) are in local geomagnetic coordinates. GPR and FSJ are closely spaced yet show significant differences, whose origins are discussed in the text.

08:48, which was noted by Connors et al. (2011) to have little effect at either the ground or in the tail more distant than geosynchronous orbit, and similarly has very weak signals in the data shown. A two-step dipolarization at GOES 11 at 09:02 and 09:09 was noted to have counterparts in midnight sector observations both at three THEMIS spacecraft near $-11 R_{\mathrm{E}}$ and on the ground. Here, $X$ dropped by nearly $500 \mathrm{nT}$ at FSJ between 08:58 and 09:00, which is earlier than the first dipolarization time mentioned. This change was not accompanied by significant change at the nearby GPR magnetometer, so it may be inferred to be quite localized. The rate of change in $X$ at FSJ decreased at 09:00, but $Z$ in the next two minutes at that station increased by about $500 \mathrm{nT}$. In a simple two-dimensional picture of electrojets, a $Z$ increase would indicate motion of the electrojet to the south of the detecting station. At the GPR station to the south (and east), the $Z$ change immediately after 09:00 is small, suggesting being near the center of the enhanced current, but the negative $X$ signal is smaller in magnitude than at FSJ, which is not consistent with this conclusion. The most likely explanation is that the positive $Z$ seen at FSJ was enhanced by the westward electrojet curling around this station. A similar situation was presented by Baumjohann and Opgenoorth (1983). These authors also suggest that an upward field-aligned current is centered in the middle of this vortical current flow structure. This would explain the $+Y$ perturbation observed to the SE at GPR, with its maximum around 09:05. The Fukushima (1976) Theorem suggests that in ideal circumstances one should not observe such field-aligned current effects; however the uniform and isotropic conductivity assumed there (Fukushima's basic theorem is a statement of Ampere's Law in a symmetric 


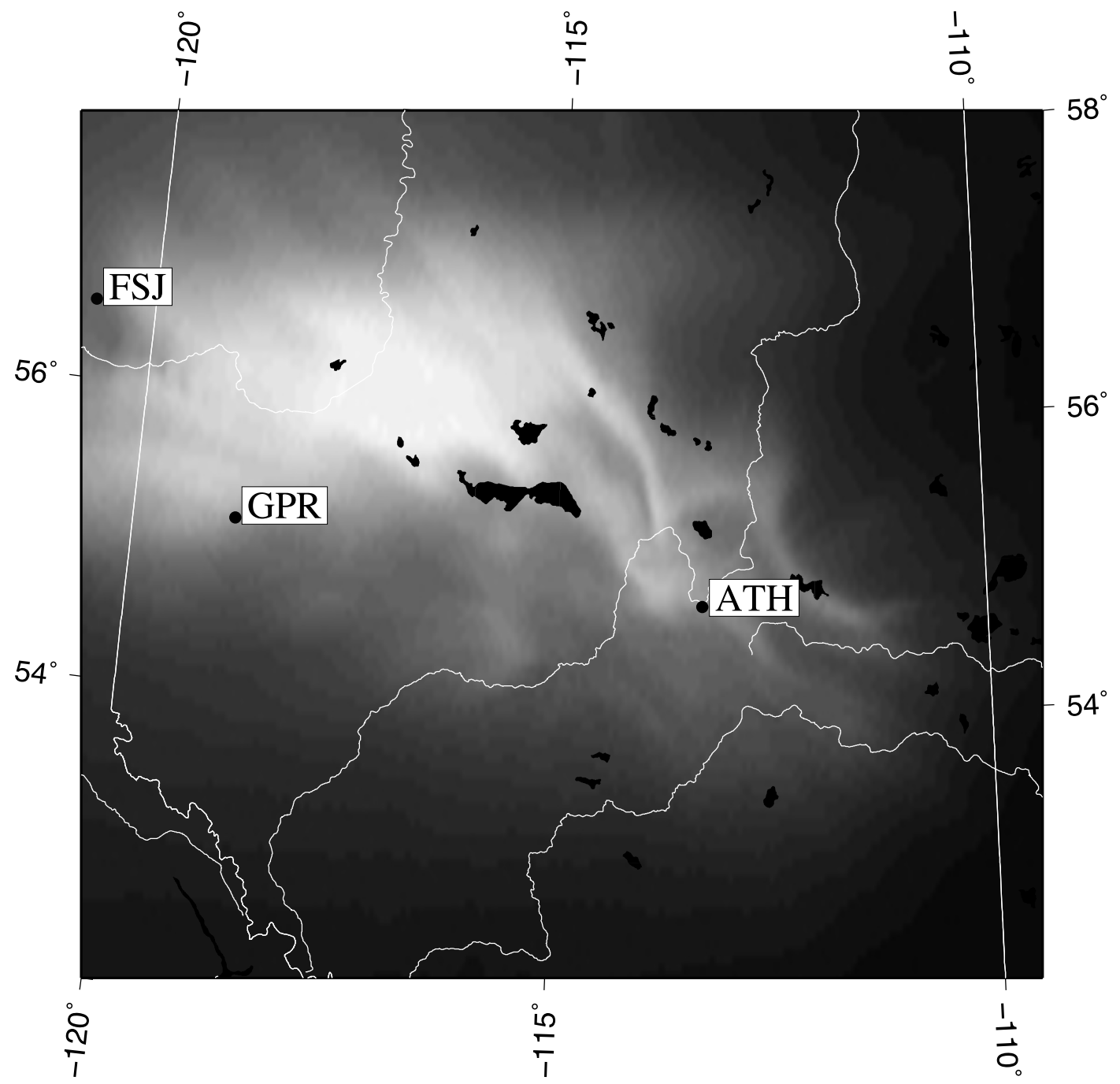

Fig. 12. Relative auroral emission intensity within view of Athabasca on April 5, 2010 at 09:05 UT in the 557.7 nm emission line, shown over a map centered on central Alberta. Major rivers and political boundaries are shown as white lines, and lakes as black regions. The wider context of the map may be found by reference to Fig. 9. Regions of little or no emission are shown in black, and the most intense emission is shown in white.

case) is far from what is found in a real auroral event, so that our suggestion that the $Y$ perturbation is a field-aligned current effect is not inconsistent. Auroral imaging backs up this claim.

The auroral emission within view of the Athabasca all-sky camera, mapped assuming an emission height of $110 \mathrm{~km}$, is shown relative to geographic features and stations ATH, GPR, and FSJ in Fig. 12. Much of the $557.7 \mathrm{~nm}$ emission is due to precipitating electrons and thus represents regions of upward field-aligned current. The emission pattern shown substantiates the presence of a region of upward field-aligned current north of Grande Prairie (GPR) as inferred from the magnetic measurements discussed above. We now investigate magnetic data from ATH to complement the observations from GPR and FSJ and to see if NPM sensors showed nonlinearity during the event.

\subsection{Linearity of sensors during a large auroral event}

The main Athabasca observatory (AUGO) has a UCLA SMALL fluxgate magnetometer whose designation is ATH, and at times has housed several NPMs under test and calibration. At the time of the April 5, 2010 event, one NPM was in operation near the ATH fluxgate. Due to the very large perturbations during this event, we can determine whether the NPM sensors deviate significantly from linearity during the largest expected magnetic events. In addition, we can add to the above discussion about field-aligned currents.

The NPM had been roughly calibrated against the SMALL magnetometer using a linear transformation. The aim of this study was to recalibrate it and see if that calibration held up in a quantitative fashion during the period of very large perturbations. Since the input signal at the two magnetometers (the SMALL as standard and the NPM as instrument under calibration) is the same, the correlation coefficient is determined at zero lag and is denoted simply as the linear correlation coefficient or Pearson $r$ (Press et al., 1992):

$$
r=\frac{\sum_{i}\left(x_{i}-\mu_{x}\right)\left(y_{i}-\mu_{y}\right)}{\sqrt{\sum_{i}\left(x_{i}-\mu_{x}\right)^{2}} \sqrt{\sum_{i}\left(y_{i}-\mu_{y}\right)^{2}}} .
$$

If the NPM sensor shows linear response, the value of $r$ should be 1 (or -1 ), and the counts may be converted to 


\section{ATH / NPM10 April 52010}
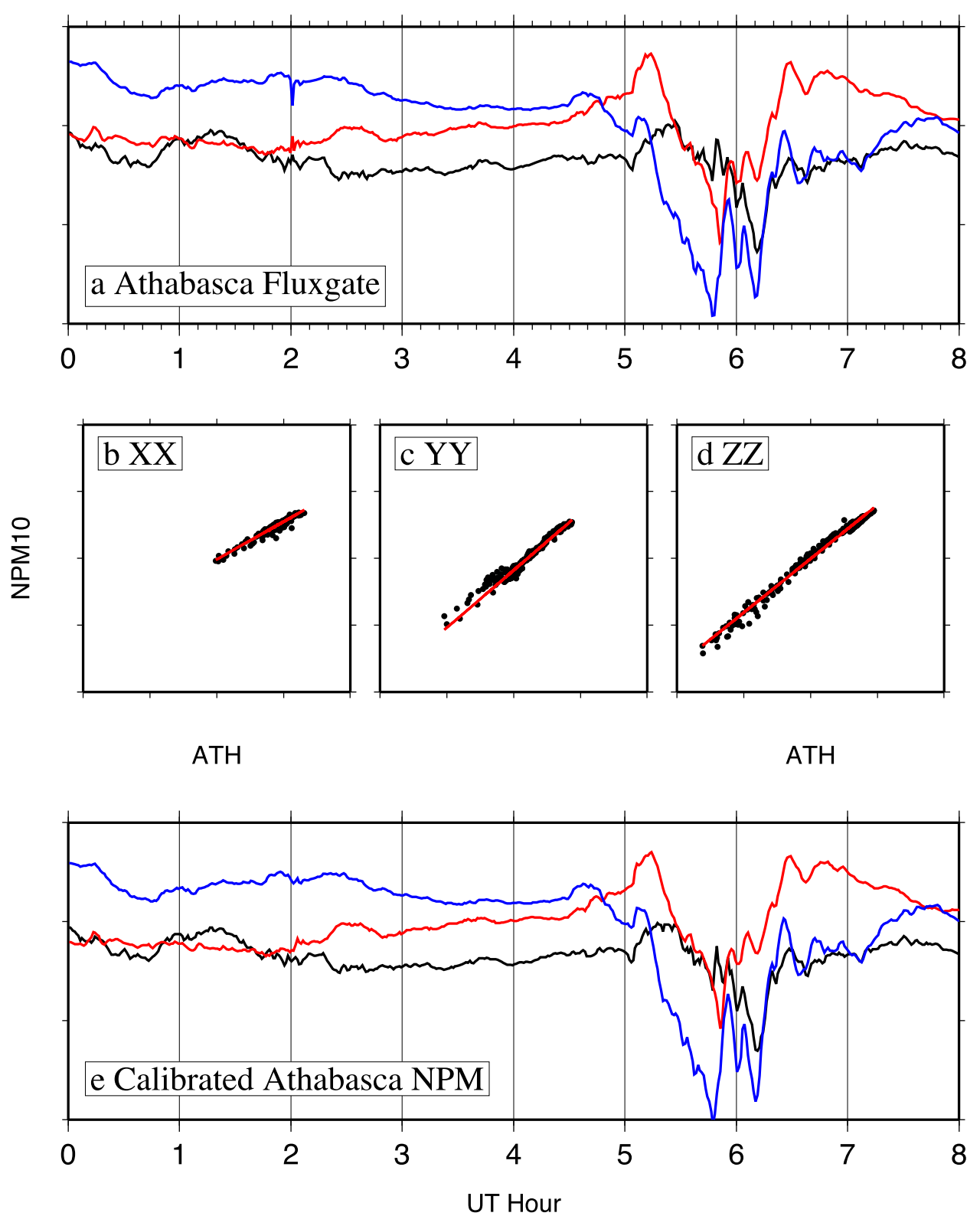

Fig. 13. Magnetic perturbations and correlations during the first 8 UT hours of April 5, 2010 at Athabasca. (a) SMALL fluxgate magnetometer data. Time scale is in hours with subdivisions 10 minutes. Vertical scale is marked at $100 \mathrm{nT}$ intervals. The $X$ component is shown in black, $Y$ component in red, and $Z$ component in blue. (b), (c), (d) correlation of SMALL data and roughly calibrated NPM data, nT on both axes indicated in $100 \mathrm{nT}$ intervals. (e) NPM results after calibration based on SMALL data, plotted as in (a).

magnetic units (here nT) by a linear transformation which may be determined by least-squares optimization. Nonlinear response would be able to be modeled by adding higher order terms, but this is undesirable if not needed. Magnetic perturbations from the period 0 to 8 UT on April 52010 are shown in Fig. 13. The perturbations had a range of less than $300 \mathrm{nT}$ during this moderately disturbed period. We expect that perturbations of this order should be sensed within the linear response of the NPM sensor. The central panels show the relation of points from the same time from the SMALL and NPM, with good linear relations. The linearity is supported by $r$ correlation coefficients of $0.973,0.976$, and 0.993 in $X, Y$, and $Z$ respectively. Linear relations de- rived from fitting allow conversion of the NPM data into calibrated nT as shown in the bottom panel. It is clear that these perturbations reflect those measured with the SMALL magnetometer with a high degree of accuracy. The initial rough calibration has been improved by use of data from this interval. The possible nonlinearity can be examined by repeating the calibration operation during the active period during 8 to $10 \mathrm{UT}$. The corresponding steps are shown in Fig. 14. While the $X$ and $Z$ components of the calibrated data are very similar to those measured by the SMALL instrument, the $Y$ scaling appears to be too large and the shape of the $Y$ curve is slightly different. While the $r$ coefficients for $X$ and $Z$ remained very high at 0.994 and 0.972 , respec- 


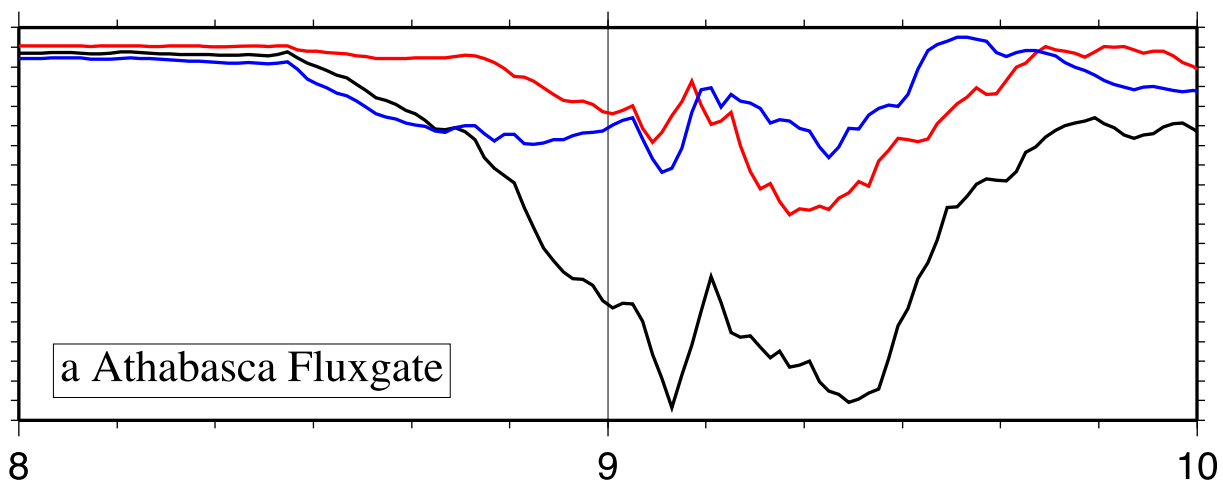

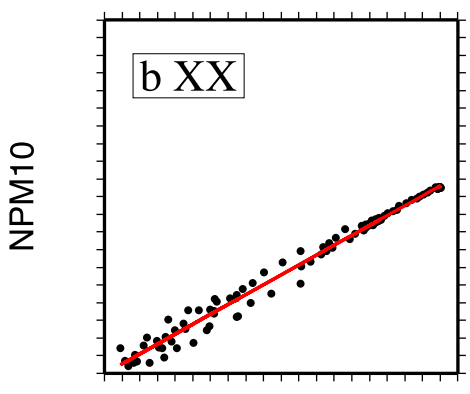

ATH
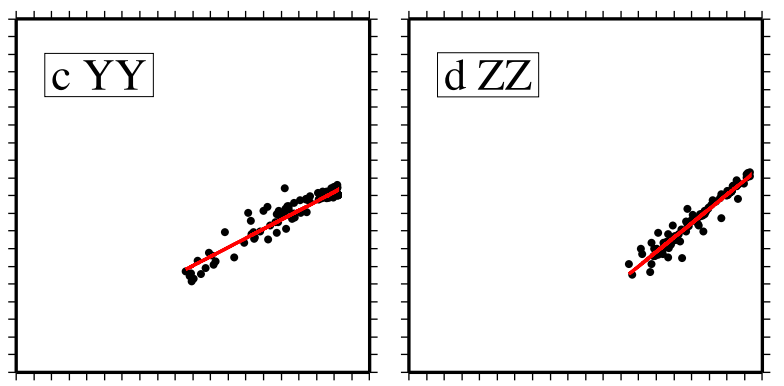

ATH

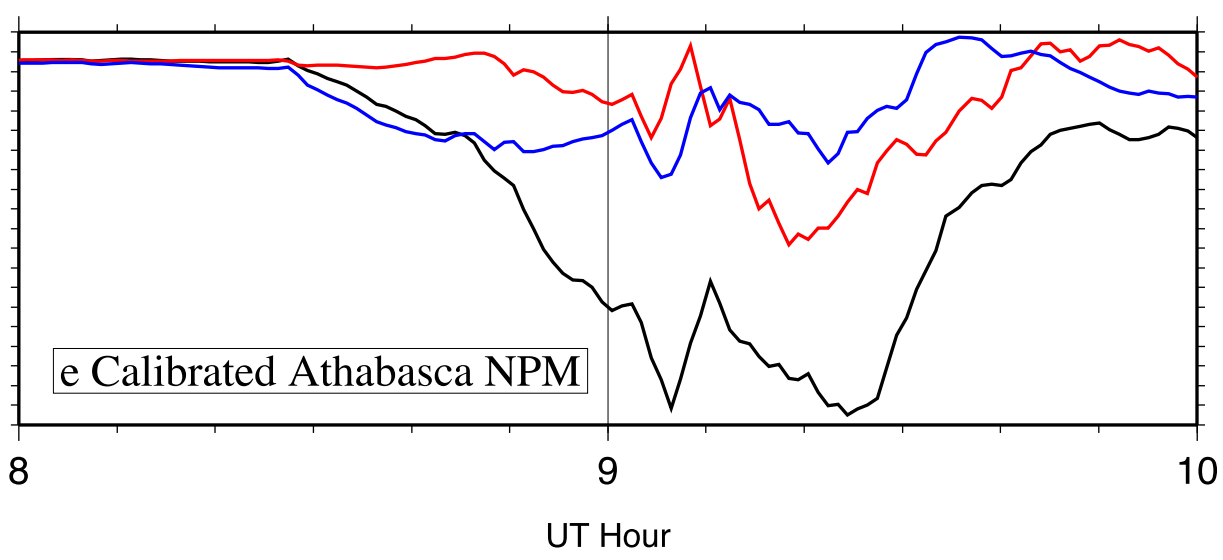

Fig. 14. Magnetic perturbations and correlations on April 5, 2010, 8 to 10 UT at Athabasca. Panels as in Fig. 13.

tively, the $Y r$ coefficient decreased to 0.953 . The $Y$ scaling changed by about $40 \%$ compared to that found for the earlier interval and is clearly not correct. We attribute this to factors which are not related to sensor nonlinearity. The $Y$ component during the active interval is smaller relative to $X$ than during the earlier interval. Slight misalignment of the two sensors results in some of the large $X$ component perturbation appearing in $Y$, in proportion to the sine of the angle of misalignment. The $X$ and $Z$ components are affected to a much lesser degree by misalignment. The result is that the detected $Y$ signal is different in SMALL and NPM for reasons not directly to do with the sensor. It would be possible to solve for, and remove, the effects of misalignment, but that goes beyond our intent in this study. The large perturbations in $X$ and $Z$ have been well reproduced, confirming that within the range of signals reasonably expected, the NPM response is linear.

One other aspect of examining the ATH data is that the positive $Y$ noted to have been present at GPR near 9 UT was not present at ATH. From the auroral imaging, the upward current region was inferred to be west of ATH and would not have caused a $Y$ component perturbation in the period prior to 09:10 UT. A field-aligned current effect similar to that observed at GPR is absent. Since the SMALL magnetometer is known from years of use to be well aligned with magnetic coordinates, its indication of a negative $Y$ perturbation at this time instead indicates downward field aligned current north of ATH. With the onset at 09:09 UT, this effect became more pronounced, with a large increase in the magnitude of the (negative) $Y$ component. This was due to the downward field-aligned current of the substorm current wedge (McPherron et al., 1973) whose westward electrojet lay northwest of Athabasca as evidenced by the enhanced (negative) $X$ perturbation at $\mathrm{CMO}$ at this time (Fig. 11). 


\subsection{Implications from April 5, 2010 event}

This section has given only an indication of what can be inferred from closely spaced stations in an auroral event. It is not intended as an exhaustive analysis of the ground signatures from the April 5, 2010 event. The implication is that closely spaced stations near intense aurora (as observed to be present in the region using the Athabasca all-sky camera) may be used to infer details of the current flow, a conclusion already reached many years ago by Baumjohann and Opgenoorth (1983). Having wider coverage enhances the chances of having data at interesting places; having denser coverage enhances the ability to interpret the data. We further note that the Scandinavian Magnetic Array (Küppers et al., 1979) had relatively dense coverage on the subcontinental scale of Scandinavia but that the ability to efficiently manage digital data has since greatly improved, enhancing the value of digital magnetometers (such as ours) which may now be used to implement such arrays.

\section{Low-Cost Arrays of Magnetic Instruments}

We have shown examples in which event interpretation was enhanced by wider and denser coverage by magnetometers. For phenomena in which spacing of $250 \mathrm{~km}$ would be useful, this could be attained in many regions of northern Canada where instruments could be sent by post, and where Internet connectivity is available, Canada's 10 million square kilometers could be covered by about 160 instruments. The cost of implementing this, assuming local participation on a volunteer basis, would be only about $\$ 80,000$ in instrumentation. Our present Grande Prairie instrument was delivered and then installed by a local colleague, and one could envisage participation from local residents interested in science and/or education. The new technology we have used would allow extensive data coverage at extremely low cost. Much new insight could be obtained with smaller scale dense arrays. A 13 by 13 array of 169 magnetometers could cover a region of 600 by $600 \mathrm{~km}$ and allow observers to watch the onset of events and their phase and group propagation, providing a giant "TV screen" for watching ionospheric currents and magnetic pulsations. The deployment of such a system would be practical in rural regions under the auroral and subauroral ionosphere, such as are found in some regions of Canada and other northerly countries.

\section{Conclusions}

Tests demonstrating the performance of a networked, 3axis, 1-sps, digital pulse counting fluxgate magnetometer have produced data that show close correlation with data collected from a research-grade UCLA-built SMALL $1 \mathrm{~Hz}$ fluxgate magnetometer. With a material cost of approximately USD $\$ 500$, the NPM offers a high cost to performance ratio with $1 \mathrm{nT}$ resolution and $1 \mathrm{~Hz}$ data sampling of three axes, which is considered the minimum standard for a research-grade instrument. Many projects could take advantage of the NPM, either as a teaching tool that allows students to work with real, locally-produced scientific data or in the development of large scale magnetic sensor networks that would be cost prohibitive using current instrumentation.
We have also demonstrated a generally usable microcontroller-based platform which could transmit data to either a local or remote archiving computer. Deployed stations have operated continuously and reliably for several years. This suggests that the low-cost, lowpower and reliable approach we have implemented for magnetometer data gathering may be widely applicable in gathering any data with a relatively slow sampling rate. With some minor technical improvements and minimal funding, and by approaching potential cooperating bodies at the appropriate administrative level, we hope to be able to meet the goal of having a much denser network of magnetometers in Canada.

Acknowledgments. Data for Fig. 10 was obtained from the Principal Investigator of the CANOPUS magnetic array at the time, Gordon Rostoker. Fort St. John magnetometer operations are conducted in cooperation with Kanji Hayashi (University of Tokyo, retired) with the support of Neil Thompson. The AUTUMN Red Deer magnetometer is operated through the cooperation of Dr. B. Martin (King's University College), and Mrs. E. Martin. USGS $\mathrm{CMO}$ data was obtained through Intermagnet. Mapping of auroral camera data was done with the help of Emma Spanswick. Thanks to Ali M. Al-Asadi (Grande Prairie Regional College) for obtaining and installing a NPM (GPR). We acknowledge CDAWeb for access to data, J. H. King and N. Papatashvilli for OMNI data, and the Government of Canada through the Canadian Space Agency and NRCan for magnetometer data (including partial funding of auroranet.org development). NPM instruments were developed using support associated with a Canada Research Chair. Implementation of cross-correlation analysis was aided by code placed online by P. Bourke at http://local.wasp.uwa.edu.au. Special thanks to Jill Mattock at Paul Rowe Jr./Sr. High School and the information technology staff at the Peace River School District for their installation and testing of the first school-installed NPM.

\section{References}

Angelopoulos, V., The THEMIS mission, Space Sci.Rev., 141(1/4), 5-34, 2008

Baumjohann, W. and H. J. Opgenoorth, Electric fields and currents associated with active aurora, in Magnetospheric Currents, edited by T. A Potemra, 357 pp., AGU, Washington, 1983.

Baumjohann, W. and R. A. Treumann, Basic Space Plasma Physics, 329 pp., Imperial College Press, London, 1997.

Box, G. E. P. and G. M. Jenkins, Time Series Analysis (Revised Edition), 575 pp., Holden-Day, Oakland, 1976.

Bredeson, C. and M. Connors, Enhancing the study of the aurora using low-cost magnetometers, Can. Undergrad. Phys. J., 2(2), 9-13, 2004.

Connors, M., J. Ponto, and M. Foote, Assessment of pulse counting magnetometer technology for solar-terrestrial environment monitoring, $A G U$, Fall Meeting 2002, SM21B-0544, 2002.

Connors, M., C. T. Russell, and V. Angelopoulos, Magnetic flux transfer in the 5 April 2010 Galaxy 15 substorm: An unprecedented observation, Ann. Geophys., 29, 619-622, doi:10.5194/angeo-29-619-2011, 2011.

Digi International Inc., RabbitCore RCM4000 C-Programmable Analog Core Module With Ethernet: User's Manual, http://ftp1.digi.com/ support/documentation/019-0157_J.pdf, 2010.

D-Link Corporation, DWL-P200 Data Shet, ftp://ftp10.dlink.com/pdfs/ products/DWL-P200/DWL-P200_ds.pdf, 2004.

Frigo, M. and S. G. Johnson, The design and implementation of FFTW3, Proc. IEEE, 93, 216-231, 2005.

Fukushima, N., Ground magnetic effect of field-aligned currents connected with ionospheric currents, Geophys. Res. Lab. Rep., UT-GRL-76-01, University of Tokyo, 1976.

Gao, Y. F., et al., Sino-magnetic array at low latitudes (SMALL) including initial results from the sister sites in the United States, Adv. Space Res., 25(7/8), 1343-1351, 2000.

Garmin International Inc., GPS 18 Technical Specifications, http://www8. garmin.com/manuals/425_TechnicalSpecification.pdf, 2005.

Kisabeth, J., On calculating magnetic and vector potential fields due to 
large-scale magnetospheric current systems and induced currents in an infinitely conducting earth, in Quantitative Modeling of Magnetospheric Processes, edited by W. P. Olson, 655 pp., AGU, Washington, 1979.

Kivelson, M. G., ULF waves from the ionosphere to the outer planets, in Magnetospheric ULF Waves, edited by K. Takahashi et al., 359 pp, AGU, Washington, 2006.

Küppers, F., W. Untiedt, W. Baumjohann, K. Lange, and A. G. Jones, A two-dimensional magnetometer array for ground-based observations of auroral zone electric currents during the international magnetospheric study (IMS), J. Geophys., 46, 429-450, 1979.

McPherron, R. L., C. T. Russell, and M. P. Aubry, Satellite studies of magnetospheric substorms on August 15, 1968. 9. Phenomenological model for substorms, J. Geophys. Res., 78, 3131-3149, 1973.

Microchip Technology Inc., Microchip PIC18FXX2 Data Sheet, http:// ww1.microchip.com/downloads/en/DeviceDoc/39564c.pdf, 2006.

National Marine Electronics Association (U.S.), NMEA 0183 Standard for Interfacing Marine Electronic Devices, NMEA, New Bern, NC, 2002.

O'Brien, T. P. and M. B. Moldwin, Empirical plasmapause models from magnetic indices, Geophys. Res. Lett., 30, doi:10.1029/2002GL016007, 2003.

Peticolas, L. M., et al., The time history of events and macroscale interactions during substorms (THEMIS) education and outreach (E/PO) program, Space Sci. Rev., 141(1/4), 557-583, 2008.

Petrinec, S. M. and C. T. Russell, Near-Earth magnetotail shape and size as determined from the magnetopause flaring angle, J. Geophys. Res., 101, 137-152, 1996.

Postel, J., User datagram protocol, RFC 768, IETF, http://tools.ietf.org/ html/rfc768, 1980.

Press, W. H., S. A. Teukolsky, W. T. Vetterling, and B. P. Flannery, Numer- ical Recipes in C, 994 pp., Cambridge, New York, 1992.

Runov, A., V. Angelopoulos, M. Sitnov, V. A. Sergeev, R. Nakamura, Y. Nishimura, H. U. Frey, J. P. McFadden, D. Larson, J. Bonnell, K.-H. Glassmeier, U. Auster, M. Connors, C. T. Russell, and H. J. Singer, Dipolarization fronts in the magnetotail plasma sheet, Planet. Space Sci., 59, 517-525, doi:10.1016/j.pss.2010.06.006, 2011.

Russell, C. T., A brief history of solar-terrestrial physics, in Introduction to Space Physics, edited by M. G. Kivelson and C. T. Russell, 568 pp., Cambridge University Press, Cambridge, 1995.

Russell, C. T. et al., THEMIS ground-based magnetometers, Space Sci. Rev., 141(1/4), 389-412, 2008.

Samson, J. C., Geomagnetic pulsations and plasma waves in the earth's magnetosphere, in Geomagnetism, v. 4, edited by J. A. Jacobs, 832 pp., Academic Press, New York, 1991.

Schofield, I. S. and D. A. Naylor, Control and communications system for remote operation of an infrared radiometer, Publ. Astron. Soc. Pacific, 119, 661-668, 2007.

Singer, H. J., Multisatellite observations of resonant hydromagnetic waves, Planet. Space Sci., 30, 1209-1218, 1982.

Speake \& Co. Llanfapley., FGM-series Magnetic Field Sensors (datasheet), http://www.speakesensors.com, 2010.

Tsyganenko, N., A magnetospheric magnetic field model with a warped current sheet, Planet. Space Sci., 37, 5-20, 1989.

Vacquier, V., Many jobs, Ann. Rev. Earth Planet. Sci., 2, 1-17, 1993.

I. Schofield (e-mail: ian.schofield@athabascau.ca), M. Connors, and C. T. Russell 